\title{
Generalized Parameters of Porous Materials as Similarity Numbers
}

\author{
Leonid Titelman (1) \\ Department of Chemical Engineering, Ben-Gurion University of the Negev, Beer Sheva, Israel \\ Email: Titelman_leonid@hotmail.com
}

How to cite this paper: Titelman, L. (2021) Generalized Parameters of Porous Materials as Similarity Numbers. Advances in Materials Physics and Chemistry, 11, 177-201. https://doi.org/10.4236/ampc.2021.1111017

Received: September 9, 2021

Accepted: November 5, 2021

Published: November 8, 2021

Copyright $\odot 2021$ by author(s) and Scientific Research Publishing Inc. This work is licensed under the Creative Commons Attribution International License (CC BY 4.0).

http://creativecommons.org/licenses/by/4.0/

\begin{abstract}
In the multifactorial preparation of porous materials, the simultaneous/sequential influence of a number of technological variables changes the individual parameters of the texture of the material (surface area, volume, pore size, etc.) to different values and with increase or decrease. Generalized parameters (GPs) combine these changes; new dependencies arise. GPs behave like the dimensionless similarity numbers known in science and technology (Reynolds, etc.). They split the data (phenomena) into series with similar properties, reveal special patterns and structural nuances. New GPs proposed. The average pore size is presented as the product of two GPs: the dimentionless shape factor $\mathrm{F}$ and pore width of unknown shape (reciprocal of the volumetric surface). Using F, for example, the SBA-15 dataset (D. Zhao, Science 1998) was split into 3 series of samples differing in synthesis temperatures, unit cell parameters, intra-wall pore volumes, pore lengths, and the ratios of wall thickness to pore size. A surprising phenomenon was discovered one of the copolymers acts in a similar way to high temperatures. The standard deviation (STD, \%) of the texture parameter in the series is its serial GP. The surface topography (micropore volume per $\mathrm{m}^{2}$ ) is proposed; it eliminates fluctuation in material density and has a lower STD than $\mathrm{cm}^{3} / \mathrm{g}$. Examples of the use of GPs for silica, carbon, alumina and catalysts are given. A correlation has been shown between the efficiency of some catalytic reactions (adsorption) and GPs. GPs provide new information about materials and open up new research challenges.
\end{abstract}

\section{Keywords}

Generalized Parameter, Similarity, Pore Shape, Porous Materials, Surface Topography

\section{Introduction}

Similarity numbers (Reynolds, Peclet, Bodenstein, etc.), well known in science 
and technology, are in fact generalized variables that combine simple measurable parameters. For example, Re combines the inside diameter of a channel with the flow rate and kinematic viscosity of the fluid. Similarity numbers divide the phenomenon under study into series with similar properties; for instance, Re divides flows into laminar, turbulent and unstable. We assumed that the generalized parameters (GPs) of porous materials, both known (but not identified as GP) and those proposed by the author in recent decades ([1] [2] [3], https://doi.org/10.3762/bxiv.2020.89.v1), behave like similarity numbers.

The independent generalized variable $X$ [2] covers all process variables (conditions of synthesis and post-synthesis treatment: reagents, temperature, pressure, time, etc.) and can be represented by the number (designation) of the sample, experiment, run, batch. When a set of processing and texture data is sorted by some texture parameter " $y$ " (surface area, pore volume, pore size, etc.) as a key (in Excell or similar program), the $X$ part turns out to be equivalent conditions for obtaining equal or close the values of this parameter; you can choose the most economical $X$ and significantly reduce the dataset [3].

The generalized parameters of the texture of porous materials were deduced as follows. The $t / D_{p}$ ratio [1] was proposed for the OMM-s (ordered porous materials); $t$ is the average wall thickness, $D_{p}$ is the average pore diameter. This GP is based on the statistical theory of the strength of solid products: the larger the body, the greater the likehood of defects arising due to the applied force. As a parameter affecting strength, $t / D_{p}$ is known from the works on cellular solids [4], thin silica films [5] and even cakes [6]. The expected by us defects of porous materials were: first, part of the SBA-15 micropore volume $V_{m i}$ [1], and then part of the closed intra-wall pore volume $V_{i w}$ of ordered mesoporous materials [3].

$V_{w} / V_{p}$ was obtained from the ideal gas equation of state [2]; it was preceded by the expression $P V_{p}=$ const. ( $P$-mechanical strength of the catalyst) confirmed for many materials and strength test methods [7].

$V_{W}=S_{B E T}{ }^{*} t$-estimate of the apparent volume of the wall [3]; $V_{i w} / V_{W}$ is a part of the intra-wall pores of ordered materials that are inaccessible to reagents [3]. $D_{p} / D_{h}$-roughness factor [3] obtained from the formula for the hydraulic diameter of round pore $D_{h} ; L_{v}=V_{p} /(\pi / 4) D_{p}^{2}$ [2] and $L_{s}=S_{B E T} / \pi D_{p}$ [3] - the lengths of the adsorbate volume and the surface area of the adsorbent-were proposed for circular pores.

It can be seen that the generalized parameters consist of various simple parameters obtained by known methods for studying porous solids: adsorbents and catalysts. It was shown [3] [8] that preparing conditions selectively affect the individual parameters: some increase, others decrease. By combining individual parameters into generalized ones and testing various dependencies with their participation, we get useful, often unexpected, results.

The generalized parameter, known in many fields of science, is volumetric surface $S_{t} / V_{t}$ [9]; it is also used in porous materials, for example in metall-organic frameworks (MOF) [10] [11]; its physical meaning is the inverse pore size of an unknown shape. Comparing it with the equation for the hydraulic diameter of 
circular pore $D_{h}=4 V_{p} / S_{p}$, one can see their closeness. This makes it possibile to propose new important GPs, both related to the pore shape and not depending on the shape.

The GP category includes such simple and dimensionless parameters as part of the surface area of micropores $S_{m i} / S_{t}$ and part of the volume of micropores $V_{m i l} / V_{i}$ they do not refer to the mass of the material. It is interesting to study their behavior in a series of samples in comparison with the specific (i.e. per gram of the mass) $S_{m i}$ and $V_{m i}$.

GPs can isolate unusual samples from a set or/and split the set into separate series. Unusual samples (without indicating their unusualness) can be seen in in our work [3] (Figure 1, Figure 6 and Figure 7).

The purpose of this article is to expand the number of GPs and demostrate the ability of GPs to behave like similarity numbers. The focus is on differences in samples structure within a series.

\section{More Generalized Parameters: $V_{m i} / S_{B E T}$, STD (\%) as Serial GP, Shape Factors $F$ and $F_{d}$, Length Indices $L_{s i}$ and $L_{v i}$}

\subsection{Generalized Parameter $V_{m i} / S_{B E T}$ as Surface topography and Its Standard Deviation (STD, \%) as a Serial Generalized Parameter}

Both the surface area of the micropores $S_{m i}$ and their volume $V_{m i}$ are measured for 1 gram of material, i.e. in $\mathrm{m}^{2} / \mathrm{g}$ and $\mathrm{cm}^{3} / \mathrm{g}$, respectively. These dimensions reflect the fact that in a series of experiments, technological variables change not only the geometry of the pores, but also the density of the solid material.

Referring to some published studies, we found that often the ratios of micropore volume $V_{m i}$ to total surface area $S_{B E T}$ are very close within a series of samples [https://doi.org/10.3762/bxiv.2020.89.v1]. This is manifested in low values of STD, \%. Going deeper into this issue, we came to the conclusion that $V_{m i} / S_{B E T}$ can be a useful characteristic of surface topography, which is a kind of roughness [12].

Micropores are located on the surface of the meso/macropores, and their surface is part of the total surface area (let's take it as $S_{B E T}$ ); therefore, it seems quite correct to take the ratio $\left(V_{m i} / S_{B E T}\right), \mathrm{cm}^{3} / \mathrm{m}^{2}$, in order to exclude fluctuation in the density of materials, but to take into account fluctuations in the total surface. The difference between the values of the standard deviation (STD, \%) $V_{m i}$ $\left(\mathrm{cm}^{3} / \mathrm{g}\right)$ and $V_{m i} / S_{B E T}\left(\mathrm{~cm}^{3} / \mathrm{m}^{2}\right)$ may indicate the presence of through micropores, closed intra-wall space $V_{i w}[3]$ and surface cracks.

In a broad sense, STD can be applied to a series of any parameters in any process, therefore it is a general purpose serial generalized parameter.

\subsection{Generalized Pore Shape $F\left(F_{d}\right)$}

Let us represent the expression for the hydraulic pore size as

$$
D_{h}=F *\left(V_{t} / S_{t}\right)
$$


If $V_{t}, S_{t}$ and $D_{h}$ have dimensions $\mathrm{cm}^{3} / \mathrm{g}, \mathrm{m}^{2} / \mathrm{g}$ and $\mathrm{nm}$ respectively, $F$ will be 2000, 4000 , and $6000, \mathrm{~nm}^{*} \mathrm{~m}^{2} / \mathrm{cm}^{3}$, for slit, circular and spherical pore models. If the volume, surface area and size are mesured in the same linear units, for example in $\mathrm{m}^{3} / \mathrm{g}, \mathrm{m}^{2} / \mathrm{g}$ and $\mathrm{m}$, respectively (we denote such a factor as $F_{d}$-dimensionless), then for the above forms, the $F_{d}$ will be Equations (2), (3) and (4). Consequently $F_{d}=0.001 F$.

$D_{h}$ is often used as the average pore diameter $D_{p}$ [13] [14] [15]. Substituting $D_{p}$ instead of $D_{h}$ in Equation (1), we obtain the equation "in separated variables"

$$
D_{p}=F_{d} *\left(V_{t} / S_{t}\right)
$$

thus, the average pore diameter is the product of two generalized factors. the dimensionless pore shape factor $F_{d}$ and the size factor $V_{t} / S_{t}$ (volume per unit surface or average adsorbate thickness) of the pore of indefinite shape. The last factor has the dimension of length. That is, it is generalized pore size. This size represents the size of a family of pores of any shapes, but with an equal $V_{t} / S_{t}$ ratio.

When the average pore size $D_{p}$ is measured (calculated) without assuming some pore shape (BJH, DFT models; TEM images, etc.), we can calculate $F$ (or $\left.F_{d}\right)$ using Equation (3).

$$
F_{d}=D_{p} * S_{t} / V_{t}
$$

In [https://doi.org/10.3762/bxiv.2020.89.v1], examples are given with $F_{d}$ from 1 to 14 , that is, from fragmented slit shape $\left(F_{d}<2\right)$ to highly corrugated one $\left(F_{d} \gg 6\right)$. If $F_{d}$ is in the range from 2 to 4 , we can calculate the percentage of slotted and circular pore shape motifs (slotted motifs $-100 *\left(4-F_{d}\right) / 2$, \%, circular motifs $=\left(100 *\left(F_{d}-2\right) / 2, \%\right)$; similarly, for $F_{d}=4 \div 6$ percent of circular and spherical motifs can be estimated by the formulas: $\left(100 *\left(6-F_{d}\right) / 2\right.$, \%. and $\left(100 *\left(F_{d}-4\right) / 2\right), \%$, respectively.

Equation similar to (3) can be proposed for micropores pore range $\left(D_{m i}<2\right.$ $\mathrm{nm})$

$$
f_{m i}=D_{m i} *\left(S_{m i} / V_{m i}\right)
$$

The factor $V_{m i} / S_{m i}$ (with the dimension of length), which we called the generalized size of micropors does not contain mass, and its STD can be compared with STD of both $S_{m i}\left(\mathrm{~m}^{2} / \mathrm{g}\right)$ and $V_{m i}\left(\mathrm{~cm}^{3} / \mathrm{g}\right)$ in a series of samples.

\subsection{Pore Length Indices $L_{s i}, L_{v i}$}

Earlier, formulas for the length of circular pores were proposed: the length of the volume of the adsorbate $L_{V}$ [2] and the length of the surface of the adsorbent $L_{s}$ [3]. The $L_{s} / L_{V}$ ratio has been adopted as a kind of rouphness factor; $L_{s} / L_{V}=1$ indicates a smooth-walled pore, the surface of which can serve as an intrinsic model of a smooth surface.

The practice of using $L_{V}$ and $L_{s}$ had shown the need to have some parameters representing the length for pores of any shape. We propose to bring the formulas for the lengths of pores of the circular shape $L_{s}=S_{B E T} \pi D_{p}$ and $L_{v}=V_{p} /(\pi / 4) D_{p}^{2}$ 
to a form suitable for any shape, simply discading $\pi$ and $\pi / 4$. Let us call these parameters the indices of length: $L_{s i}=S_{B E T} / D_{p}$ is the pore surface length index, and $L_{v i}=V_{p} / D_{p}^{2}$ is the pore volume length index.

\section{Discussion. Series, Separated Samples and Texture Nuances}

\subsection{Series of Materials}

\subsubsection{Series of Classical SBA-15}

A dataset of 11 SBA-15 samples from the classic work Zhao et al. ([16], table 1, p. 550), containing such processing variables as copolymers, reaction temperature, temperature and heating time after synthesis, was supplemented with $F_{d}$, $L_{V i}, t / D$ and $V_{i w}$. It was found that at a reaction temperature of $60^{\circ} \mathrm{C}$ and without post-synthesis heating, a series of samples with the smallest unit cell parameters $a_{o}$ and close to a circular pore shapes $F_{d}$ were obtained. To check for other series, the dataset was sorted by $F_{d}$ as a key. All data can be divided into series A, B, C (Table 1).

The series obtained at specified temperatures and times differ in: 1) the pore shape factor $F_{d}$, 2) the $a_{o}$ parameter, 3) $t / D_{p}$, 4) the pore volume length index $L_{v i}$ and 5) the intra-wall pore volume $V_{i w}$. Interestingly, the largest volume of closed intra-wall pores $V_{i w}(4.05 \div 4.32)$ correlates with the largest $t / D_{p}$ value, and the highest $F_{d}\left(6 \div 6.5\right.$, spherical shape) with the lowest $L_{v i}(1.04 \div 1.74)$.

The nuance in the behavior of the $\mathrm{EO}_{5} \mathrm{PO}_{70} \mathrm{EO}_{5}$ copolymer (series $\mathrm{C}$, sample no. 1) in comparison with the long-chain $\mathrm{OE}$ of other copolymers $\left(\mathrm{EO}_{17} \div \mathrm{EO}_{26}\right)$ requires additional research. This copolymer affects the properties of SBA-15 in the same way as heating after synthesis at elevated temperatures: $80^{\circ} \mathrm{C}$ for $48 \mathrm{~h}$ (note: $80^{\circ} \mathrm{C}$ for $24 \mathrm{~h}$ was in series $\mathrm{B}$ ), $90^{\circ} \mathrm{C}$ and $100^{\circ} \mathrm{C}$ for $24 \mathrm{~h}$. Possibly, with such heating, long $\mathrm{EO}_{17}-\mathrm{EO}_{26}$ chains are shortened to $\mathrm{EO}_{5}$.

Table 1. Synthesis conditions and textural properties of SBA-15 samples divided into series A, B and C by shape factor $F_{d}$. Based on Zhao et al. [16] data.

\begin{tabular}{cccc}
\hline Series & $\mathrm{A}$ & $\mathrm{B}$ & $\mathrm{C}$ \\
\hline $\begin{array}{c}\text { Generalized shape factor } F_{d} \\
\text { \#\# samples from }([16] \text {, table } 1)\end{array}$ & $4 \div 5$ & $5 \div 6$ & $6 \div 6.5$ \\
$\begin{array}{c}\text { Reaction and post-synthesis } \\
(+) \text { temperatures, }{ }^{\circ} \mathrm{C}\end{array}$ & 60 & $\left.35 ; 35+80^{*}\right) ; 40$ & $\begin{array}{c}\left.35+E O_{5} ; 35+80^{* *}\right) ; \\
\left.\left.35+90^{*}\right) ; 35+100^{*}\right)\end{array}$ \\
$a_{o}, \mathrm{~nm}$ & $8.60 \div 9.31$ & $11.26 \div 12.01$ & $12.10 \div 13.60$ \\
$L_{v i}{ }^{*} \mathrm{E}-10, \mathrm{~m} / \mathrm{g}$ & $3.42 \div 4.99$ & $2.22 \div 3.31$ & $1.04 \div 1.74$ \\
$t / D_{p}$ & $0.58-0.79$ & $0.78-1.45$ & $0.36-0.54$ \\
$V_{i w}, \mathrm{~cm}^{3} / \mathrm{g}$ & $2.78 \div 3.50$ & $4.05 \div 4.32$ & $1.83 \div 3.20$ \\
\hline
\end{tabular}

$\mathrm{EO}_{5}$-copolymer $\left.\mathrm{EO}_{5} \mathrm{PO}_{70} \mathrm{EO}_{5} ;{ }^{*}\right)$ heating for $24 \mathrm{~h},{ }^{* *}$ ) heating for $48 \mathrm{~h}, \mathrm{a}_{0}$-unit cell parameter, $L_{V i}$-pore volume length index, $t$-wall thickness, $D_{P}$-average pore size, $V_{i w}-$ intrawall pore volume. 


\subsubsection{Series of Thin-Walled and Thick-Walled SBA-15}

Klimova et al. [17] prepared 8 SBA-15 samples using only one triblock copolymer $\mathrm{EO}_{20} \mathrm{PO}_{70} \mathrm{EO}_{20}$ by varying the synthesis temperature $\left(35,60^{\circ} \mathrm{C}\right)$, the postsynthesis aging temperature $\left(60,80^{\circ} \mathrm{C}\right)$ and the aging time $(24,48 \mathrm{~h})([17]$, Table 1, p. 333). Finally, all samples were calcined at $550^{\circ} \mathrm{C}$.

Even the original data, namely the dependence of the wall thickness $t$ on the sample (run) number X (Figure 1, tall bars), show that there are two samples No. 1 and No. 5 with close values of wall thickness $t(5.2$ and $5.0 \mathrm{~nm})$, which are markedly different from the rest of the samples $(t=3.8 \div 4.3 \mathrm{~nm})$.

Nuance. An amazing fact is that one of the samples (\#5) was synthesized and aged at the lowest temperatures and times $\left(35^{\circ} \mathrm{C}-60^{\circ} \mathrm{C}-24 \mathrm{~h}\right)$, and the second $(\# 1)$ at the highest $\left(60^{\circ} \mathrm{C}-80^{\circ} \mathrm{C}-48 \mathrm{~h}\right)$. Recall that all samples were then calcined.

STD as an indicator of the sensitivity of parameters. To obtain additional information about the samples, we used dimensionless $t / D_{p}, V_{w} / V_{p}, F_{d}$, intra-wall pore volume $V_{i w}$ [3], and length indices $L_{s i} L_{v i}$. Analysis of STD, \%, of all these properties showed that the largest STD: $27 \%$ and 26\%, have $t / D_{p}$ and $V_{w} / V_{p}$ respectively. This means that these parameters are the most sensitive to the processing conditions.

The dependence of $t / D_{p}$ on $X$ is shown in Figure 1 low posts.

The average values of the thicknesses $t$ of the thick $(5.1 \mathrm{~nm})$ and thin $(4.05$ $\mathrm{nm}$ ) walls were calculated and then their ratio was taken as 5.1/4.05 $=1.26$. The same was done for $t / D_{p}: 1.03 / 0.62=1.67$. The latter is noticeably higher, i.e. the generalized parameter $t / D_{p}$ provides better separation than just the thickness $t$. STDs of $t$ and $t / D_{p}$ were in range $2.8 \% \div 5.7 \%$.

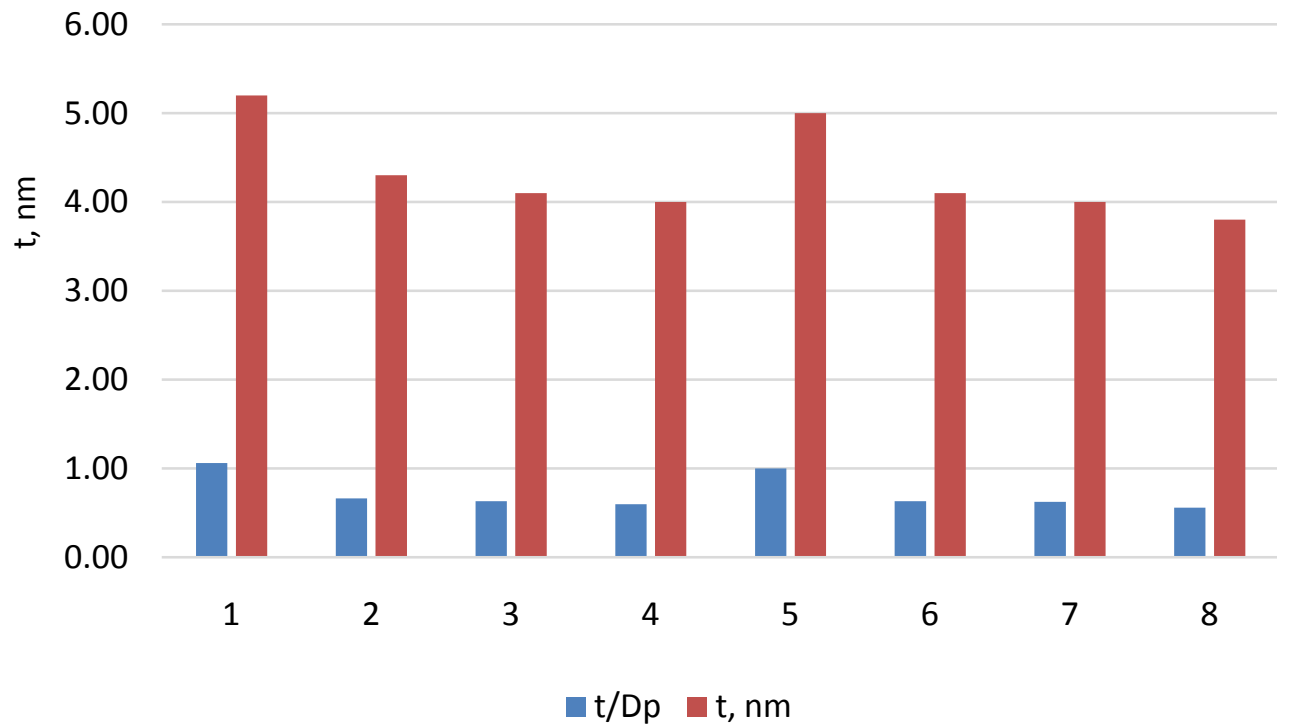

Figure 1. Dependence of the SBA-15 texture parameters $t$ (tall bars) and $t / D_{p}$ (low bars) on the generalized processing variable $X$ (sample or run number). According to Klimova et al. [17] data. 
The same feature is emphasized by the dependence of the pore shape factor $F_{d}$ on $V_{w} / V_{p}$ (Figure 2): the parameter $V_{w} / V_{p}$ separates a couple of the thickest specimens, signaling their difference from the rest.

In addition, a correlation can be seen between $V_{w} / V_{p}$ and the pore shape of thin-walled SBA-15. The possible differences in all their textural properties were checked for thick-walled samples \#\#1 and 5. Among the properties, the most noticeable difference was shown by $S_{m i} S_{B E T}(0.286$ and 0.148$)$. High temperatures and time have led to an increase in the proportion of micropores. It can be assumed that under these conditions a crust penetrated with micropores is formed.

The minimal STD (3.2\%) has $S_{B E T}$, apparently due to constant triblok copolymer; in Zhao work [16] with several copolymers it was $15.3 \%$.

\subsubsection{The Length Index Separates 18 Samples MCM-41 to 2 Series}

Putz et al. [18] synthesized 18 samples of MCM-41 by hydrolysis of TEOS in water and a mixture of water with 2-methoxyethanol. The technological variables were: catalyst $\left(\mathrm{NH}_{3}\right.$ or $\left.\mathrm{NaOH}\right)$, template (CTAB, DTAB or their mixture), temperatures and time (hours) of processing after synthesis $\left(60^{\circ} \mathrm{C}-9 \mathrm{~h}, 500^{\circ} \mathrm{C}-6\right.$ h, $700^{\circ} \mathrm{C}-6 \mathrm{~h}$ ). Texture parameters $S_{B E T}, V_{p}$ and $D_{p}$ were presented. We have calculated the shape factor $F_{d}$ the range of $F_{d}$ was $1.280 \div 6.126$, that is, from less than 2 (fragmentary slit shape) to more than 6 (spherical shape). The index of the surface length of the samples was calculated $L_{s i}=S_{B E T} D_{p}$. It turned out that this parameter divides 18 samples into two series of materials only: with 10 short $\left(L_{s i}=4.2 \mathrm{E}+8 \div 3.4 \mathrm{E}+9\right)$ and 8 by two orders of magnitude longer $\left(L_{s i}=7.1 \mathrm{E}+10\right.$ $\div 1.7 \mathrm{E}+11), \mathrm{m} / \mathrm{g}$, pores.

\subsubsection{Silica Foam Series. Lack of Intra-Wall Porosity}

Schmidt-Winkel et al. ([19], tables 1, 2 and 3) prepared 30 samples of siliceous cellular foams with "well defined ultra-large mesopores". Processing variables were: ratio of silica source to template, aging temperature $\left(100,120^{\circ} \mathrm{C}\right)$ and addition of $\mathrm{NH}_{4} \mathrm{~F}$ (with or without).

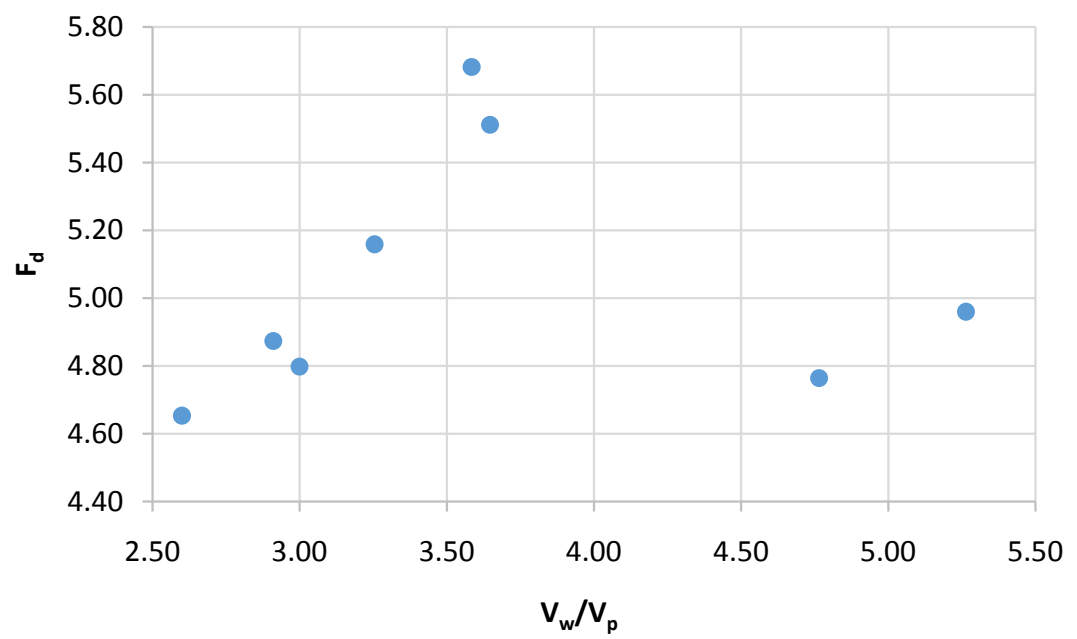

Figure 2. SBA-15. $V_{w} / V_{p}$ versus $F_{d}$. Points $V_{w} / V_{p}=4.76$ and 5.26 refer to thick-walled samples \#5 and \# 1 respectively. According to Klimova et al. [17] data. 
The texture parameters include $S_{B E T}, V_{p}$, the average diameter of the cellular foam sphere $D_{s}$, the diameter of the cells $D_{o}$ the diameter of the windows $D_{w}$, and (which is rarely given but very important for us) the overal porosity $P_{o}$.

The shapes of the pores were checked. It turned out that it is windows that create channels. $D_{w}$ can be modeled with circular pores, that is, $D_{p}=D_{w}$. The only sample No.18 has slit pores $\left(F_{d}=2.46\right)$, for other samples $F_{d}=3.5 \div 5.0$. The dependence of the pore shape factor $F_{d}=D_{w} * S_{B E T} T V_{p}$ on $S_{B E T}$ clearly separates the samples into series (Figure 3 ). Those grouped by $S_{B E T} \approx 400 \mathrm{~m}^{2} /$ g were synthesized at $120^{\circ} \mathrm{C}$ and with the addition of $\mathrm{NH}_{4} \mathrm{~F}$.

Nuance. Then the apparent volume of the wall $V_{w}=V_{p}\left(1 / P_{o}-V_{p}\right)$ was calculated [2]. It turned out that all samples have $V_{w}=0.44-0.46 \mathrm{~cm}^{3} / \mathrm{g}$, that is, they have a specific volume of a silica skeleton (silica density is $1 / 0.45=2.2 \mathrm{~g} / \mathrm{cm}^{3}$ ). In other words, there is no $V_{i w}$-intra-wall porosity inside the foam walls.

Using $V_{w}$ the parameters $t / D_{w}$ and $t$ were estimated [2]. The range of wall thicknesses was $1.74 \div 4.50 \mathrm{~nm}$. The separated sample No. 18 has the highest value $t=4.5 \mathrm{~nm}\left(t / D_{w}=0.36\right)$. The same sample turned out to be one of two samples isolated from the bulk of the samples in the $t / D_{w}$ vs. $V_{w} / V_{p}$ diagram (Figure 4).

The point $V_{w} / V_{p} \approx 0.32$ belong to the sample \#1, which has the smallest diameters of foam spheres, cells and windows.

\subsection{Microporous Materials Series}

\subsubsection{Effect of Host Microporosity}

Zukerman et al. [20] compared two $\mathrm{TiO}_{2} / \mathrm{SBA}-15 \mathrm{NO}$ conversion catalysts. 2 batches of SBA-15 with different duration of hydrothermal treatment (1 and 3 days): SBA-15HM with high $\left(V_{m i} / V_{t}=14.2 \%\right)$ and SBA-15LM with low (4.7\%) microporosity were synthesized. Time was the first variable. Then the guest $\mathrm{TiO}_{2}$ phase was introduced into both carriers by internal hydrolysis in equal amounts. The second variable was the $\mathrm{TiO}_{2}$ content $(0 \% ; 8 \% ; 23 \% ; 38 \%$ and $50 \%)$. Thus,

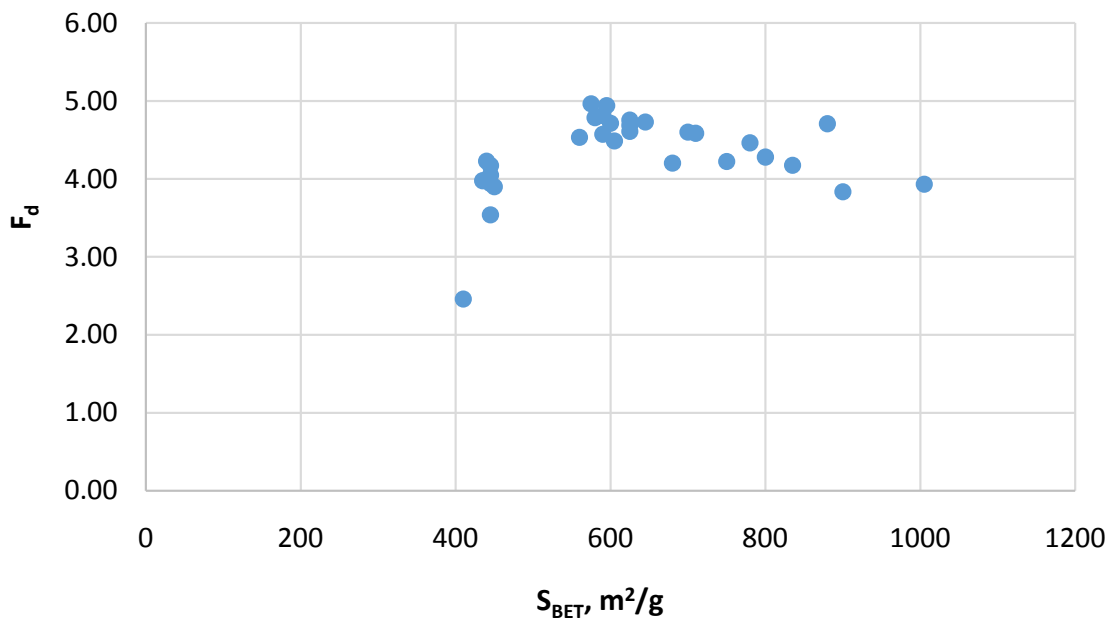

Figure 3. Silica cellular foams; dependence of $S_{B E T}$ on pore shape factor $F_{d .}$. Based on Schmidt-Winkel et al. [19] data. 


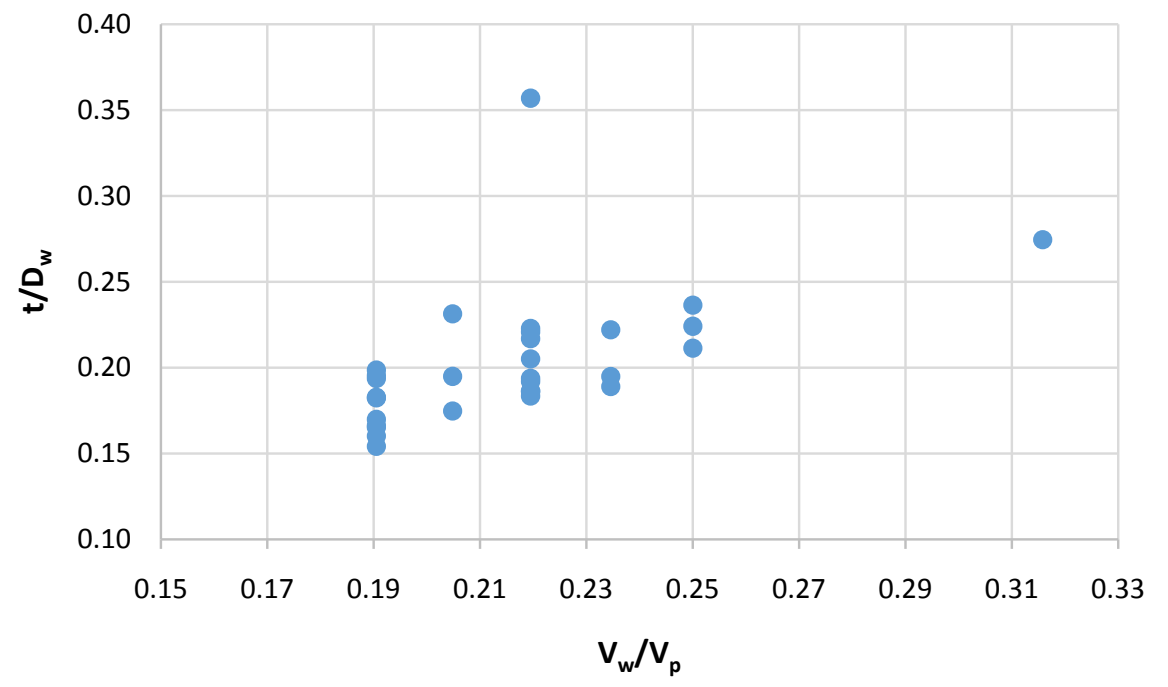

Figure 4. Dependence of $t / D_{w}$ on $V_{w} / V_{p}$ for 30 samples of siliceous foam. Based on Schmidt-Winkel et al. [19] data.

the dataset consisted of 2 series of 5 samples each. Sample $50 \% \mathrm{TiO}_{2} / \mathrm{SBA}-15 \mathrm{HM}$ was the best; it has the highest both $\mathrm{V}_{2} \mathrm{O}_{5}$ uptake and NO conversion. The texture properties are given: $S_{B E T}\left(\mathrm{~m}^{2} / \mathrm{g}\right), V_{t}\left(\mathrm{~cm}^{3} / \mathrm{g}\right), S_{m i}\left(\mathrm{~cm}^{3} / \mathrm{g}\right), V_{m i}\left(\mathrm{~cm}^{3} / \mathrm{g}\right), V_{m i} / V_{t}$ (\%), $D_{p}$ (NLDFT, nm). In this work, generalized parameters: $V_{t} / S_{B E T}, S_{m i} / S_{B E T}$, $V_{m i} / S_{B E T}, V_{m i} / S_{m i}, F_{d}, L_{s i}, L_{v i}$ were calculated. $S T D$, \%, was determined for each parameter of both series (SI).

It was found that the percentage of micropores effects on the pore shape of the host: high- and low-microporous SBA-15 have factors $F=6233$ ( $\approx$ spherical shape) and 4993 (50\% spherical and 50\% cylindrical motifs), respectively. The inclusion of $\mathrm{TiO}_{2}$ did not affect the pore shape: $S T D$ of $F$ was only $3.2 \%$ for HM and $2.1 \%$ for LM. The influence of the $\mathrm{TiO}_{2}$ content on the fluctuations in the parameters of micropores is established in Table 2; $D_{P}$ and $V_{t} / S_{B E T}$ are shown for comparison with $V_{m i} / S_{m i}$

The distributions (STDs) of the parameters of the samples in the two series behave markedly differently. In the highly porous (HM) series, both the $S_{m i}\left(\mathrm{~m}^{2} / \mathrm{g}\right)$ and $V_{m i}\left(\mathrm{~cm}^{3} / \mathrm{g}\right)$, associated with mass, fluctuate (STD $\left.=53.1,55.5 \%\right)$ more than those associated with the surface, $S_{m i l} S_{B E T}, V_{m i l} S_{B E T}(\mathrm{STD}=37.7 \%, 41.1 \%$, respectively). It is possible that their positive differences $\left(\triangle S T D S_{m i}=15.5 \%\right.$ and $\triangle S T D V_{m i}=14.5 \%$ ), i.e. better connection $S_{m i}$ and $V_{m i}$ with mass of material than with surface, indicate the existence of through micropores. This is also evidenced by the rather narrow (6\%) deviation of the generalized size of micropores $V_{m i l} / S_{m i}$.

In a series with a small number of micropores, $S_{m i}$ and $V_{m i}$ change in opposite directions: $\triangle S T D S_{m i}$ is positive but $\triangle S T D V_{m i}$ is negative, i.e. micropores are more scattered over the surface than over the depth of the mass. Apparently, these micropores are surface cracks. The very high fluctuation of the generalized size of micropores $V_{m i} / S_{m i}(131.5 \%)$ confirms this assumption. 
Table 2. Influence of the volume of micropores SBA-15 (host) on the $S T D$ of the texture parameters of the $\mathrm{TiO}_{2} / \mathrm{SBA}^{-15}$ catalyst.

\begin{tabular}{|c|c|c|c|c|c|c|c|c|c|}
\hline \multirow{3}{*}{ Host sample } & \multicolumn{7}{|c|}{ Parameter of $\mathrm{TiO}_{2} / \mathrm{SBA}-15$} & \multirow{2}{*}{\multicolumn{2}{|c|}{ Difference $\Delta$}} \\
\hline & $S_{m i}$ & $S_{m i} / S_{B E T}$ & $V_{m i}$ & $V_{m i} / S_{B E T}$ & $D_{p}$ & $V_{t} / S_{B E T}$ & $V_{m i l} / S_{m i}$ & & \\
\hline & & & & STD, \% & & & & $\Delta S T D S_{m i}$ & $\Delta S T D V_{m i}$ \\
\hline SBA15HM-14.2\% $V_{m i}$ & 53.1 & 37.7 & 55.5 & 41.1 & 4.0 & 4.3 & 6.0 & 15.5 & 14.5 \\
\hline SBA15LM-4.7\% $V_{m i}$ & 58.5 & 45.0 & 40.6 & 55.0 & 5.3 & 6.2 & 131.5 & 13.5 & -14.2 \\
\hline
\end{tabular}

$S T D$, \%-standart deviation of parameter in series of 5 samples; $S_{m i}, \mathrm{~m}^{2} / \mathrm{g}$-specific micropore surface area; $S_{B E T}, \mathrm{~m}^{2} / \mathrm{g}$-total specific surface area (method BET); $S_{m i} S_{B E T}, \mathrm{~m}^{2} / \mathrm{m}^{2}$ (or \%)-micropore surface area per $\mathrm{m}^{2}$ of total surface area; $\triangle S T D S_{m i}=S T D S_{m i}-$ $S T D S_{m i} / S_{B E T} ; V_{m i}, \mathrm{~cm}^{3} / \mathrm{g}$-specific micropore volume; $V_{m i} S_{B E T}, \mathrm{~cm}^{3} / \mathrm{m}^{2}$-micropore volume per $\mathrm{m}^{2}$ of total surface area; $\triangle S T D V_{m i}$ $=S T D V_{m i}-S T D V_{m i} S_{B E T}, D_{P}$-average pore size, nm; $V_{t} / S_{B E T}$-generalized pore size; $V_{m i} / S_{m i}$-generalized micropore size.

Note that in both series, the fluctuations of both the generalized pore size $V_{t} / S_{B E T}$ and the average pore diameter $D_{p}$ (4.3 and 4.0;6.2 and 5.3, respectively) are quite close, which justifies the name given to $V_{t} / S_{B E T}-$ "generalized size".

\subsubsection{Standard Deviations of Supermicropore $\left(D_{m i} \leq 1 \mathrm{~nm}\right)$ Volumes}

The smaller the pore size, the stronger the overlapping of the fields of the opposite walls and the higher the adsorption potential [21]; therefore, one can expect a stronger connection of supermicropores with the surface as compared to micropores. Gadion et al. [22], Mostazo-Lopez et al. [23] and Zubizarreta et al. [24] estimated the volumes of micropores of carbon sorbent by adsorption $\mathrm{N}_{2}$ (micropores, $D_{m i}<2 \mathrm{~nm}$ ) and $\mathrm{CO}_{2}$ (supermicropores, $D_{m i} \leq 1 \mathrm{~nm}$ ) (Table 3).

It can be seen that $V_{m i} / S_{B E T}$ is the more stable parameter than $V_{m i}$ i.e. fluctuation of the micropores as a part of the total surface area is less then fluctuation together with pore walls density. The role of the surface increases when micropore size decreases.

Nuance. The series of large $\left(D_{p}=45 \mathrm{~nm}\right)$ mesoporous carbon xerogel samples [24], treated absolutely different (activated chemically, oxidised by $\mathrm{NiNO}_{3}$, impregnated by Ni), show very small $(4.4,5.3 \%)$ and equal STDs of $V_{m i}$ and $V_{m i} / S_{B E T}$.

\subsection{Comparing Replicas with Their Templates}

1) Węgrzyniak et al. [25] prepared 8 samples of CMK-3 using SBA-15 as a template and two carbon precursors (1st variable): sucrose (CMK-3s series) and poly-furfuryl alcohol (CMK-3f series). The resulting materials were carbonized at $550^{\circ} \mathrm{C}, 650^{\circ} \mathrm{C}, 750^{\circ} \mathrm{C}$ and $850^{\circ} \mathrm{C}$ (2nd variable), and the silica was removed using a hydrofluoric acid solution.

All CMK-3s samples showed better propane to propene conversion compared to CMK-3f. $S_{B E T}, V_{p}, V_{m i}$ and PSD were given; it can be seen from the PSD (Figure 2 in [25]) that the pore diameters of both series are very close. We have calculated $V_{m i} / S_{B E T}, V_{t} / S_{B E T}$ for all samples as well as average values and standard deviations of all parameters for both series (Table 4).

First of all, note the closeness of the values of average generalized pore size $V_{t} / S_{B E T}$ in two series $(0.77,0.76 \mathrm{~nm})$, which coincides with the PSD pattern of 
Table 3. Comparison of standard deviations, \%, of $V_{m i}$ and $V_{m i l} S_{B E T}$ parameters of activated carbons (AC).

\begin{tabular}{|c|c|c|c|c|}
\hline \multirow{2}{*}{ Material } & \multirow{2}{*}{$V_{m i l} / V_{t}, \%$} & \multicolumn{2}{|c|}{ STD, \% } & \multirow{2}{*}{ Data source } \\
\hline & & $V_{m i}, \mathrm{~cm}^{3} / \mathrm{g}$ & $V_{m i} / S_{B E T}, \mathrm{~cm}^{3} / \mathrm{m}^{2}$ & \\
\hline Carbons-replicas of SBA-15, MCM- $48\left(D_{m i}<2 \mathrm{~nm}\right)$ & $26 \div 56$ & 52.0 & 8.2 & [22] \\
\hline The same $\left(D_{m i} \leq 1 \mathrm{~nm}\right)$ & $12 \div 52$ & 43.9 & 29.3 & {$[22]$} \\
\hline $\mathrm{N}$-doped Carbon electrocatalyst $\left(D_{m i}<2 \mathrm{~nm}\right)$ & 100 & 18.5 & 6.6 & {$[23]$} \\
\hline The same $\left(D_{m i} \leq 1 \mathrm{~nm}\right)$ & $40 \div 68$ & 12.1 & 12.5 & [23] \\
\hline Ni-doped carbon xerogel $D_{p}=16 \mathrm{~nm}\left(D_{m i}<2 \mathrm{~nm}\right)$ & $33 \div 52$ & 14.8 & 11.6 & {$[24]$} \\
\hline The same $\left(D_{m i} \leq 1 \mathrm{~nm}\right)$ & $23 \div 33$ & 20.4 & 16.0 & {$[24]$} \\
\hline Ni-doped carbon xerogel $D_{p}=45 \mathrm{~nm}\left(D_{m i}<2 \mathrm{~nm}\right)$ & $25 \div 35$ & 4.4 & 4.4 & {$[24]$} \\
\hline The same $\left(D_{m i} \leq 1 \mathrm{~nm}\right)$ & $16 \div 25$ & 5.2 & 5.3 & {$[24]$} \\
\hline
\end{tabular}

$D_{m i}-$ mucropore diameter, $V_{m i}=$ micropore total volume, $S_{B E T}-$ pore total surface area.

Table 4. Common and generalized parameters of the SBA-15 template and CMK-3 replicas. Based on data from Węgrzyniak et al. [25].

\begin{tabular}{cccccc}
\hline Sample & $S_{B E T, \mathrm{~m}^{2} / \mathrm{g}}$ & $V_{m i}, \mathrm{~cm}^{3} / \mathrm{g}$ & $V_{P}, \mathrm{~cm}^{3} / \mathrm{g}$ & $V_{m i l} / S_{B E T}, \mathrm{~cm}^{3} / \mathrm{m}^{2}$ & $V_{P} / S_{B E T}, \mathrm{~nm}$ \\
\hline SBA-15 & 694 & 0.04 & 0.85 & $5.8 \mathrm{E}-05$ & 1.22 \\
\hline CMK-3s series & 1658 & 0.09 & 1.27 & $5.3 \mathrm{E}-05$ & 0.77 \\
CMK-3f series & 931 & 0.01 & 0.71 & $1.1 \mathrm{E}-05$ & 0.76 \\
\hline & & \multicolumn{5}{c}{ Average } \\
\hline CMK-3s series & 2.2 & 19.5 & 10.0 & 10.9 \\
CMK-3f series & 3.1 & 0.0 & 19.1 & 3.1 & 16.8 \\
\hline
\end{tabular}

$S_{B E T}$-total surface area, $V_{m i}$-micropore volume, $V_{P}$-total pore volume.

real pore diameters. Comparing these data with $V_{t} / S_{B E T}=1.22 \mathrm{~nm}$ of SBA-15 one can see that the replica diameters are smaller then the template diameter.

The average surface rouphness $V_{m i} / S_{B E T}$ of CMK-3s, created by sucrose, $(5.3 \mathrm{E}-05$ $\left.\mathrm{cm}^{3} / \mathrm{m}^{2}\right)$ repeated that of SBA-15 $\left(5.8 \mathrm{E}-05 \mathrm{~cm}^{3} / \mathrm{m}^{2}\right)$, while poly-furfuryl alcohol creates carbon CMK-3f with a much smoother surface $\left(V_{m i} / S_{B E T}=1.1 \mathrm{E}-05\right.$ $\left.\mathrm{cm}^{3} / \mathrm{m}^{2}\right)$.

From the very low STD of $S_{B E T}(2.2,3.1 \%)$ it can be concluded that there is very little effect of carbonization temperature on the surface area of both CMKs.

2) Ponomarenko et al. [26] prepared samples of SBA-15 silica, in which the pore shape factor $F_{d}$ ranged from 4.539 to 8.721 , that is, from almost circular to very corrugated [https://doi.org/10.3762/bxiv.2020.89.v1]. Then the samples were used as templates for the fabrication of carbon OMMs. The question arises, to what extent do the latter inherit the shape of silicate nanotubes? The answer was that the pore shapes of the replicas $\left(F_{d}=3.949 \div 5.706\right)$ strongly differ from the template ones (Figure 5). 


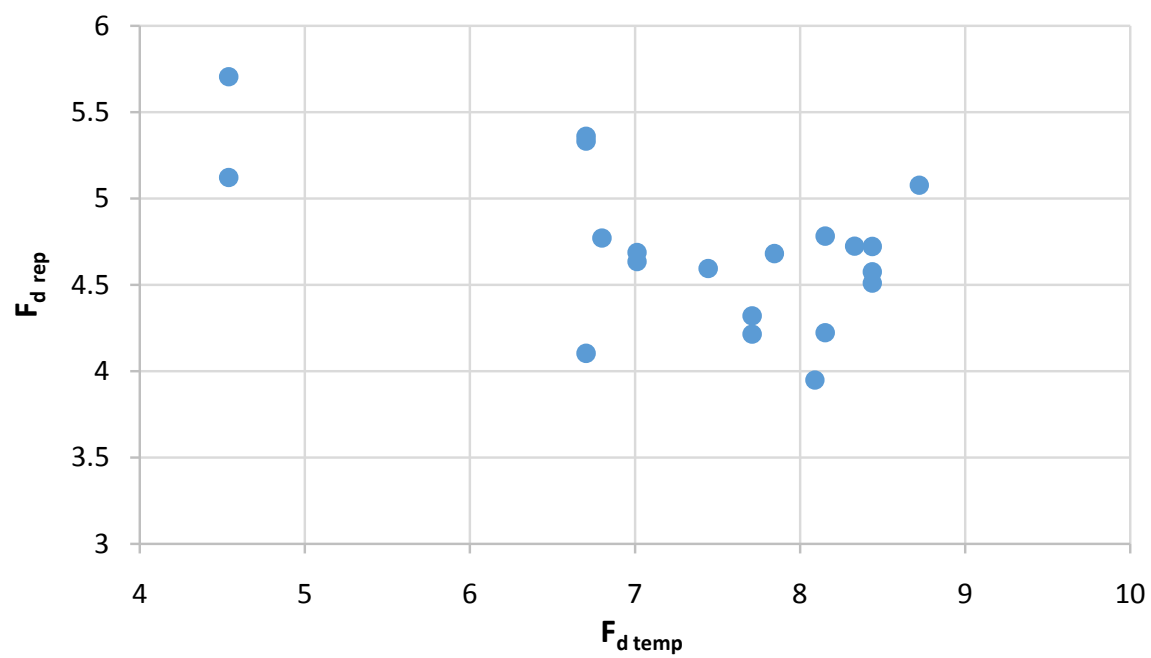

Figure 5. Shape factor of the carbon replica $-F_{d \text { rep }}$ depending on the shape factor of the

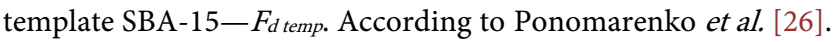

The pores of the silica matrices were spherical and corrugated $\left(F_{d t e m}=6.5 \div\right.$ $8.5)$, but the pores of carbon, as a rule, became close to circular $\left(F_{d r e p}=4 \div 5\right)$. After the dissolution of silicate, the carbon tubes elongate and expand, the pore diameter narrows; as a result, their shape becomes close to circular. Two samples at $F_{d t e m}=4.5$, stand out strongly from the mass. It was found that these carbon mateials were heated at the highest temperatures and do not have micropores (samples \#\#1 and 2 in ([26], Table on the page 81)).

\subsection{Cases of Almost Constant Surface Topography.}

1) Lee et al. [27] prepared 7 samples of ordered mesoporous carbon using MSU-H silica as a template, sucrose as a carbon source and boric acid (BA) as a pore expander. BA, \%, was the only variable. The STD-s of the terms of Equation (2): $D_{p}(\mathrm{BJH}), V_{p} / S_{B E T}$ and F were $36.8 \%, 12.5 \%$ and $26.1 \%$ respectively, i.e. this is the case when the STD for $D_{p}(36.8 \%)$ is close to the sum (38.6\%) of the STDs of the generalized shape factor $F$ and the generalized pore size $V_{p} / S_{B E T}$.

The diameters of the carbon pores were noticeably smaller, the walls were thicker and much longer than these parameters of the silica template. F-s (3175 $\div 7123$ ) are directly proportional to $\mathrm{BA}, \%$, and inversely proportional to $t / D_{p}$. $\mathrm{STD}=1 \%$ was found for $V_{m i} / S_{B E T}$ (at STD $=18 \%$ for $V_{m i}$ ).

2) Arshad et al. [28] prepared AC samples by activating an empty bunch of fruit with hot $\mathrm{CO}_{2}$ (BC sample, with circular pores) and then treating $\mathrm{BC}$ with 0.5, 1.0 and $2.0 \mathrm{M} \mathrm{KOH}$ solutions (samples $\mathrm{AC} 1, \mathrm{AC} 2$ and $\mathrm{AC} 3$ respectively). When using $0.5 \mathrm{M} \mathrm{KOH}$ solution and converting BC to AC1, the $S_{B E T}$ and $V_{p}$ parameters increased by a factor of $10-15$, but $D_{p}(\mathrm{BJH})$ decreased from 2.4 to $1.9 \mathrm{~nm}$. The question arises how did $S_{B E T}$ and $V_{p}$ increase? To explain this phenamenon, we checked the pore shape factor $F_{d}$ and length $L_{s}$.

It was found that materials $\mathrm{BC}$ and $\mathrm{AC}(\mathrm{AC} 1, \mathrm{AC} 2$ and $\mathrm{AC} 3)$ have the same circular pore shape $\left(F_{d} \approx 4.0\right)$, therefore, the pore shape cannot be the cause of 
these changes. As for the length $L_{s}$ of the pore volume, it increased 17 times, which explains the increase in $S_{B E T}$ and $V_{p}$. These parameters and $V_{m i}$ are directly proportional to $L_{s}$. Stretching the walls leads to an increase in $V_{m i}\left(\mathrm{~cm}^{3} / \mathrm{g}\right)$ by a factor of 2.5 , but the $V_{m i} / S_{B E T}\left(\mathrm{~cm}^{3} / \mathrm{m}^{2}\right)$ values of samples AC1, AC2 and AC3 differ very little $(\mathrm{STD}=4.9 \%)$, i.e. all $\mathrm{KOH}$ solutions provide the same surface topography.

Comparing STDs of $V_{p}$ with $V_{p} / S_{B E T}(41.85 \%$ and $4.03 \%), S_{m i}$ with $S_{m i} / S_{B E T}$ (39.49\% and $1.95 \%)$ and $V_{m i}$ with $V_{m i} / S_{B E T}(43.41 \%$ and $4.9 \%)$ one can conclude that $\mathrm{KOH}$ effects strongly on parameters connected with mass but very little on parameters connected with total surfaces.

3) Alam and Mokaya [29] prepared 6 samples of microporous zeolite-like carbons using zeolite $\mathrm{Y}$ as a hard template, liquid impregnation of it with furfuryl alcohol, followed by chemical vapour deposition (CVD) of acetonitrile at temperatures of $700^{\circ} \mathrm{C} \div 950^{\circ} \mathrm{C}$. $V_{m i} / V_{p}$ were $75 \%-83 \%$, STD of $V_{m i}=25.2 \%$ and STD of $V_{m i} / S_{B E T}=2.4 \%$, that is, all temperatures resulted in approximately the same surface topography.

\section{5. $V_{m i} / S_{B E T}$ as only Sensitive Parameter}

Pagketanang et al. [30] obtained activated carbon (AC) from rubber seed shells by activating $\mathrm{KOH}$, washing with water, and calcining in a stream of $\mathrm{N}_{2}$ at temperatures $T_{c}=700^{\circ} \mathrm{C}, 800^{\circ} \mathrm{C}$ and $900^{\circ} \mathrm{C}$ (samples AC700, AC800 and AC900). $S_{B E T}, V_{p}, D_{p}$ and $V_{m i}$ data were presented. We tested dependencies $V_{m i}, F_{d}, L_{s i}$ and $V_{m i} / S_{B E T}$ on $T_{c}$. The pore shape factor $F_{d}$ turned out to be inversely proportional to $T_{\mathcal{O}}$ while $L_{s i}$ and $V_{m i}$ were directly proportional to it (not shown), therefore the listed parameters did not reveal anything unusual. Such a case was found usig the dependence of $T_{c}$ on $V_{m i} / S_{B E T}$ (Figure 6).

Figure 6 shows that, in contrast to the directly proportional dependence of

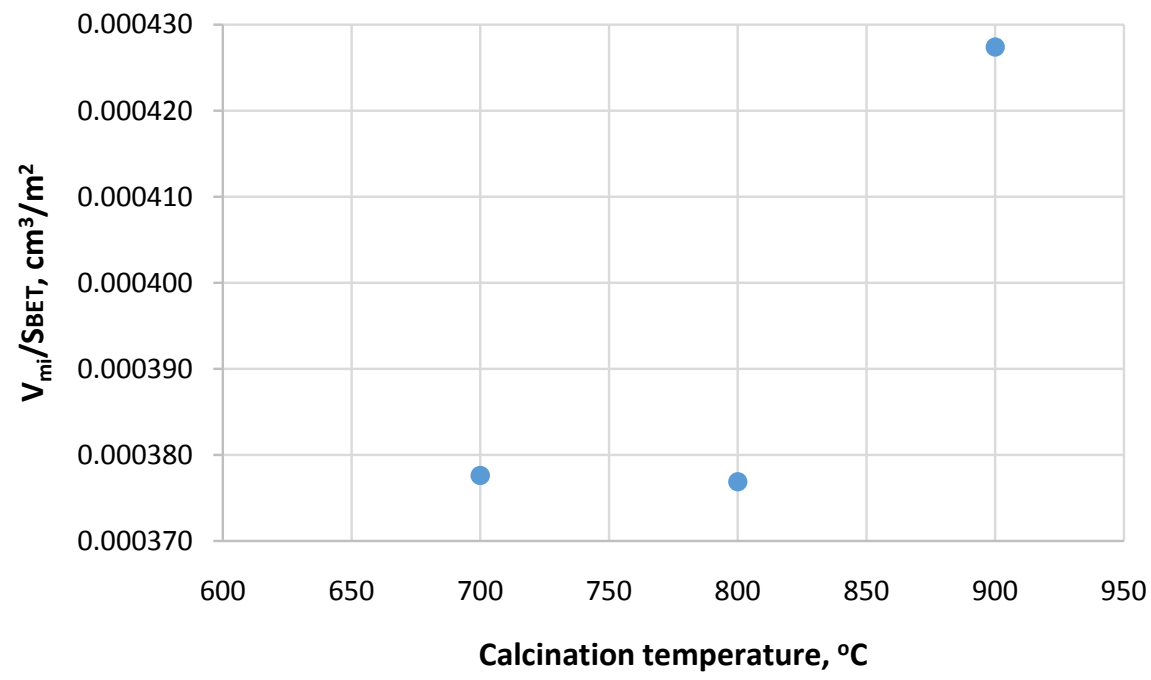

Figure 6. Activated carbon. Dependence of the $V_{m i l} S_{B E T}$ on calcination temperature. Based on Pagketanang et al. data [30]. 
$V_{m i}$ on $T_{\mathcal{O}}$ annealing from $700^{\circ} \mathrm{C}$ to $800^{\circ} \mathrm{C}$ did not change $V_{m i} / S_{B E T} . T_{c}=800^{\circ} \mathrm{C}$ distinguishes between two different mechanisms of micropore formation: up to $800^{\circ} \mathrm{C}$, the surface is formed with a constant number of micropores per $\mathrm{m}^{2}$ of surface, but then micropores are formed faster than the total carbon surface.

\subsection{Looking for a Series of Samples}

Bastos-Neto et al. ([31], Tables 1, 2) studied the adsorption (storage) of methane by 10 commercial and non-commercial activated carbons (AC). Among the samples were the sample \#8 with the lowest methane uptake $(57 \mathrm{mg} / \mathrm{g} \mathrm{AC})$ and sample \#10 with the highest absorbance (168 mg/g AC). The authors of [31] estimated $\left.V_{m i}: 1\right)$ by the Dubinin-Radushkevich method ( $\left.V_{m i} \mathrm{DR}\right)$ and 2$)$ by the Monte Carlo molecular simulation method $\left(V_{m i} \mathrm{MC}\right)$.

There schould be a direct proportionality between methane uptake $(\mathrm{mg} / \mathrm{g})$ and micropore volume $V_{m i}\left(\mathrm{~cm}^{3} / \mathrm{g}\right)$. In [31], Figure $3\left(\mathrm{CH}_{4}\right.$ vs. $\left.V_{m i} \mathrm{DR}\right)$ and Figure $4\left(\mathrm{CH}_{4}\right.$ vs. $\left.V_{m i} \mathrm{MC}\right)$ indicate the presence of at least 2 series of samples, but the diffrence between them is not discussed. In search of an explanation, the original texture properties $V_{m i}, S_{B E T}, V_{p}$, and $D_{p}(\mathrm{HK})$ were supplemented by $F_{d}$ $V_{P} / S_{B E T}, L_{v i}, L_{s i}$, and $V_{m i} / S_{B E T}$.

The graph of the dependence of the adsorption of $\mathrm{CH}_{4}$ on $V_{P} / S_{B E T}$ (not shown) made it possible to isolate only sample \#10 (with the highest absorption), its absorption corresponds to the highest $V_{p} / S_{B E T}\left(0.0011 \mathrm{~cm}^{3} / \mathrm{m}^{2}\right)$. The absorption of all other samples occurs at a constant $V_{P} / S_{B E T}=0.0006 \mathrm{~cm}^{3} / \mathrm{m}^{2}$.

Figure 7 shows the absorption of $\mathrm{CH}_{4}$ as a function of the surface topography $V_{m i} / S_{B E T}$

The 8 out of 10 samples form a cloud of close $V_{m i} / S_{B E T}$ values in a wide range of $\mathrm{CH}_{4}$ uptakes ( $80-140 \mathrm{mg} / \mathrm{g} \mathrm{AC}$ ). Samples with minimum and maximum adsorbance are clearly separated. Thus, the lowest and highest adbsorption levels are associated with the surface topography.

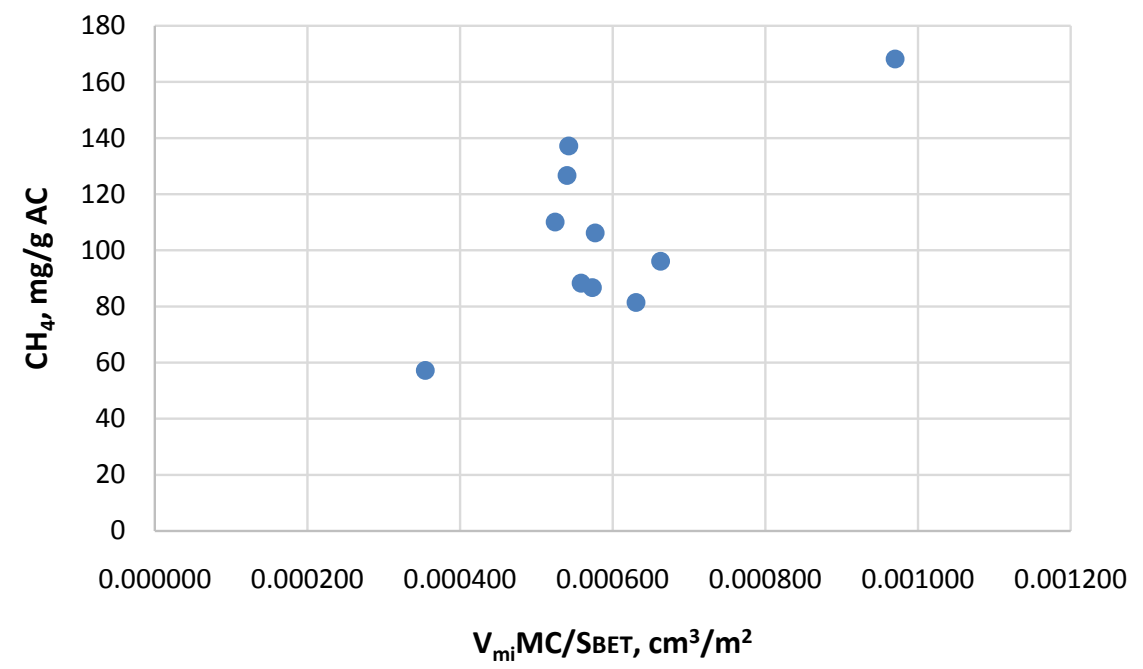

Figure 7. $\mathrm{CH}_{4}$ adsorption versus $V_{m i l} S_{B E T}$ surface topography. Based on Bastos-Neto et al. [31] data. 
Then STDs were calculated for all texture parameters. To separate a series, a parameter with a minimal deviation is needed. The minimum STD $(8.9 \%)$ was obtained for $D_{p}$. Figure 8 shows the dependence of the $\mathrm{CH}_{4}$ uptake on the average pore diameter $D_{p}$.

Two series of samples are clearly visible: series 1 with $\mathrm{CH}_{4}$ uptake inversely proportional to $D_{p}$ (low $D_{p}$ range) and series 2 with $\mathrm{CH}_{4}$ uptake independent on $D_{p}\left(D_{p}>1.31 \mathrm{~nm}\right)$. The series 1 illustrates well the potential theory of adsorption [21]; it can be said that the influence of opposite pore walls starts from $D_{p}=1.3$ $\mathrm{nm}$ and increases with its decrease.

\subsection{Incorporation of Metals into Ordered Silica}

1) $\mathrm{Al}$ inside $\mathrm{SBA}-15$

Yue et al. [32] prepared thick-walled AlSBA-15 from a mixture of tetraethylorthosilicate and aluminium tri-tert-butoxide (direct inclusion of $\mathrm{Al}$ in SBA-15, $\mathrm{Si} / \mathrm{Al}=10)$ and compared it with conventional SBA-15. Both series of materials: SBA-15 and AlSBA-15, were processed by 5 different methods (Table 5): calcination (method $\mathrm{C}$ ), heating to a high temperature with $\mathrm{O}_{2}-\mathrm{H}_{2} \mathrm{O}$ mixtures (V),
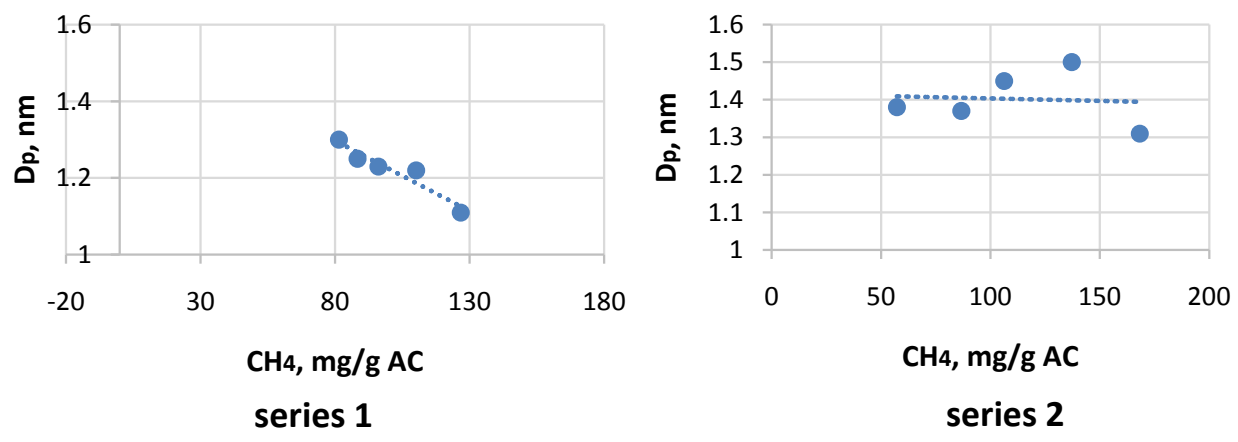

Figure 8. The dependencies of the $\mathrm{CH}_{4}$ uptake on the average pore diameter. Based on Bastos-Neto et al. [31] data.

Table 5. Influence of Al inclusion in SBA-15 and conditions processing of SBA-15 and AlSBA-15 on pore volume inside their walls $V_{i w}$, pore shape factor $F_{d}$ and parameter $t / D_{p}$. Based on materials from Yue et al. [32].

\begin{tabular}{|c|c|c|c|c|c|c|c|c|}
\hline \multirow{2}{*}{ SBA-15 } & \multirow{2}{*}{ AlSBA-15 } & \multirow{2}{*}{$\begin{array}{c}\text { Treatment } \\
\text { method }\end{array}$} & \multirow[t]{2}{*}{ SBA-15 } & \multirow[t]{2}{*}{ AlSBA-15 } & \multirow[t]{2}{*}{ SBA-15 } & \multirow[t]{2}{*}{ AlSBA-15 } & \multirow[t]{2}{*}{ SBA-15 } & \multirow[t]{2}{*}{ AlSBA-15 } \\
\hline & & & & & & & & \\
\hline Run \# & Run \# & & $V_{i w}, \mathrm{~cm}^{3} / \mathrm{g}$ & $V_{i w}, \mathrm{~cm}^{3} / \mathrm{g}$ & $F_{d}$ & $F_{d}$ & $t / D_{p}$ & $t / D_{p}$ \\
\hline 1 & 7 & --- & 3.77 & 4.57 & 5.039 & 4.856 & 0.769 & 0.676 \\
\hline 2 & 8 & $\mathrm{C}$ & 1.17 & 1.94 & 2.822 & 3.871 & 1.109 & 0.611 \\
\hline 3 & 9 & $\mathrm{~V}$ & 2.46 & 3.40 & 4.236 & 4.763 & 0.930 & 0.608 \\
\hline 4 & 10 & A & 3.98 & 4.82 & 4.522 & 5.968 & 0.797 & 0.618 \\
\hline 5 & 11 & B & 1.50 & 2.80 & 2.818 & 3.744 & 0.597 & 0.653 \\
\hline 6 & 12 & $\mathrm{~N}$ & 2.95 & 4.61 & 4.447 & 5.787 & 0.797 & 0.653 \\
\hline
\end{tabular}

C-calcination, $\mathrm{V}-$ hot $\mathrm{O}_{2}-\mathrm{H}_{2} \mathrm{O}, \mathrm{A}, \mathrm{B}, \mathrm{N}$-acidic, basic, neutral solutions; $V_{i w}$-intra-wall pore volume, $F_{d}-$ dimensionless pore shape factor, $t$-wal thickness, $D_{P}$-pore diameter. 
treatment with acid (A), basic (B), and neutral (N) solutions (12 samples in total) ([23] p. 123, table 1). Row of Table 5 contains the SBA and AlSBA samples, processed in the same way.

The direct inclusion of $\mathrm{Al}$ in SBA-15 (sample \#7 compared to \#1) leads to an increase in the volume $V_{i w}$ of intra-wall pores (4.57 against $3.77 \mathrm{~cm}^{3} / \mathrm{g}$ ). This excess remains for the entire series. Apparently, the Al film covers the surface, preventing the escape of vapors and gases from the internal cavity of the walls.

The inclusion of $\mathrm{Al}$ in SBA-15 (run \#7 vs. \#1) has virtually no effect on the pore shape of SBA-15, which is circular/spherical. In the SBA-15 series, calcination (run \#2) and basic solution (run \#5) make the pore shape of SBA-15 close to slotted $\left(F_{d} \approx 2.800\right.$ ), but the presence of Al prevents strong pore flattening and they remain almost circular (runs \#\#8 and 11).

Treatment with both acidic (A) and neutral solutions (runs \#\#4 and 6) does not affect SBA-15, but in AlSBA-15 (runs \#\#10 and 12) they transform a circular shape into a spherical one. In general, any treated AlSBA has higher $F_{d}$ value then the corresponding SBA-15. Figures $F$ vs. $V_{i w}$ for the SBA-15 and AlSBA-15 series demonstrate their direct proportionality (not shown). Table 6 shows the calculated STDs of some texture parameters for both series.

An important result of this work is the strong stabilizing effect of the introduced $\mathrm{Al}$ on the pore diameter $D_{p}$ and the parameter $t / D_{p}$, which characterizes the mechanical strength of the structure.

By comparing the STD-s of the diameters $D_{p}$ and composing them $F$ and $V_{P} / S_{B E T}$ (Equation (3)), we can conclude that processing variables affect $F$ and $V_{p} / S_{B E T}$ in opposite way; the dependence of $F$ on $V_{P} / S_{B E T}$ is inversely proportional (not shown). This once again testifies to the selective influence of processing variables on textural parameters [3] [8].

2) $\mathrm{Al}$ inside MCM-41 Walls

La-Salvia et al. [33] introduced Al into thin-walled MCM-41. MCM-41 and two samples of mesoporous materials Al-MCM-41 with different Al content (Table 7) were obtained from STAB, Al sulphate hydrate and TEOS by non-hydrothermal synthesis in an alcaline-free media at room temperature and short reaction times. The resulting material was filtered, dried and calcined. The introduction of $\mathrm{Al}$ led to increase in the unit cell parameter $a_{o}$ and wall thickness $t$ but a decrease in

Table 6. Standard deviations of SBA-15 and AlSBA-15 texture parameters.

\begin{tabular}{crrrrrrrr}
\hline & \multicolumn{8}{c}{ Parameter } \\
\cline { 2 - 9 } Series & $S_{B E T}$ & $V_{p}$ & $D_{p}$ & $t$ & $t / D$ & $F$ & $V_{P} / S_{B E T}$ & $V_{\text {iw }}$ \\
\cline { 2 - 9 } & \multicolumn{7}{c}{ STD, \% } \\
\hline SBA-15 & 35.3 & 28.7 & 14.5 & 7.0 & 20.6 & 23.5 & 29.5 & 43.7 \\
AlSBA-15 & 26.1 & 13.1 & 1.8 & 5.1 & 4.4 & 19.2 & 18.6 & 31.8 \\
\hline
\end{tabular}

$S_{B E T}, V_{P}, D_{p}$ and $t$-pores total surface area, total volume, average pore diameter correspondingly; $F$-generalized pore shape factor, $V_{p} / S_{B E T}$-generalized pore size, $V_{i w}$-intrawall pore volume. 
Table 7. Influence of $\mathrm{Al}$ incclusion in MCM-41 on the original $\left(a_{o}, S_{B E T}, V_{p}, D_{p}\right.$ and $\left.t\right)$ and calculated $\left(V_{w}, V_{i w}\right.$ and $F_{d}$ ) textural properties of materials. Based on La-Salvia et al. data ([33], p. 4, table 2).

\begin{tabular}{ccccccccccc}
\hline \multirow{2}{*}{ Sample } & $\mathrm{Al}$, & $a_{0}$, & $S_{B E T}$, & $V_{p}$, & $D_{p}$, & $t$ & $V_{w}$, & $V_{i w}$, & $F_{d}$ & $L_{v i} \mathrm{E}-11$, \\
\cline { 2 - 10 } & $\mathrm{wt} \%$ & $\mathrm{~nm}$ & $\mathrm{~m}^{2} / \mathrm{g}$ & $\mathrm{cm}^{3} / \mathrm{g}$ & $\mathrm{nm}$ & $\mathrm{nm}$ & $\mathrm{cm}^{3} / \mathrm{g}$ & $\mathrm{cm}^{3} / \mathrm{g}$ & none & $\mathrm{m} / \mathrm{g}$ \\
\hline MCM-41 & 0 & 4.02 & 1412 & 1.06 & 2.65 & 1.37 & 1.93 & 1.48 & 3.539 & 1.51 \\
Al-MCM-41(50) & 1.96 & 4.12 & 1390 & 0.97 & 2.61 & 1.51 & 2.10 & 1.64 & 3.740 & 1.42 \\
Al-MCM-41(15) & 6.25 & 4.19 & 992 & 0.68 & 2.56 & 1.63 & 1.62 & 1.16 & 3.735 & 1.04 \\
\hline
\end{tabular}

$a_{0}$ - unit cell parameter; $S_{B E T}, V_{p}$ and $D_{p}$-pore surface area, volume and diameter, $t$-wall thickness, $V_{w}$-apparent wall volume, $V_{i w}$-intrawall pore volume, $F_{d}$-pore shape factor.

$S_{B E T}$ and $V_{p}$; the pore diameter did not change (Table 7). The question is where will $\mathrm{Al}$ fits: outside or inside the walls. We added parameters $F_{d}$, the apparent volume of the wall $V_{W}=S_{B E T} * t$ and the intra-wall pore volume $V_{i w}$ [3] as well the length index of the adsorbate volume $L_{v i}$.

The $F_{d}$ values show that the pore shape did not chaged and is close to circular, the surface is slightly smoother. The most informative is the behavior of $V_{W}$ and $V_{i w}$. The addition of $1.96 \% \mathrm{Al}$ increases these volumes slightly, but the addition of $6.25 \% \mathrm{Al}$ decreases them markedly. This means that $\mathrm{Al}$ occupied part of the space inside the walls, $L_{v i}$ decreased noticeably, which also explains the reduction in $S_{B E T}$ and $V_{p}$.

3) Ti makes the pores of MCM-41 slotted

MCM-41 with the pore wall thickness $2.5 \mathrm{~nm}$ was grafted by Palumbo et al. [34] with a solution of titanocene dichloride in chloroform. The addition of only $0.65 \mathrm{wt} \% \mathrm{Ti}$ greatly changed the pore shape of MCM-41: its shape factor changes from a circular-slit $\left(F_{d}=3.134\right)$ to fragmental slit $\left(F_{d}=1.494\right)$. The change in $F_{d}$ occured as a result of a doubling of the pore volume length index $L_{v i}$, while the surface length index $L_{s i}$ remained practically unchanged.

4) Optimal Mo content

Chanchuey et al. [35] used spherical silica particles (SSP) to prepare an Al-SSP composite $(60 \mathrm{wt} \% \mathrm{Al})$. The composite was impregnated with Mo precursors to give $1 \% \mathrm{Mo} / \mathrm{Al}-\mathrm{SSP}$ and $5 \% \mathrm{Mo} / \mathrm{Al}-\mathrm{SSP}$ catalysts. The catalysts were tested in the dehydration of ethylene to ethanol. The $1 \% \mathrm{Mo} / \mathrm{Al}-\mathrm{SSP}$ catalyst had better catalytic performence ([35], Figure 7]. To find a possible relationship between catalytic activity and the textural properties of catalysts, we compiled Table 8.

It follows from the table that the largest pore diameter of $7.2 \mathrm{~nm}$ and a close to circular $(81.7 \%)$ pore shape contribute to $100 \%$ conversion of ethylene to ethanol. It can be said that catalysts also play the role of molecular sieve in both size and shape (note: sieving lipase by pore shape is shown in [https://doi.org/10.3762/bxiv.2020.89.v1]).

5) Xu et al. ([36], p. 1293, Table 1) studied the effect of the Al content on the textural properties and catalytic activity of hierarchical porous aluminosilicate materials. The best $\mathrm{Si} / \mathrm{Al}$ ratio was found to be 25 ; the material was crystallized 
Table 8. Textural properties of the Al-Si support and Mo-Al-Si catalysts for the dehydration of ethylene to ethanol. Based on Chanchuey et al. data ([35], Table 1, p. 3).

\begin{tabular}{cccccccccc}
\hline \multirow{2}{*}{ Catalyst } & $S_{B E T}$, & $V_{p}$, & $D_{p}$, & $L_{v i} \mathrm{E}-10$, & $F_{d}$ & \multicolumn{3}{c}{ Shape motive, \% } & \multicolumn{2}{c}{ Conversion, } \\
\cline { 2 - 9 } & $\mathrm{m}^{2} / \mathrm{g}$ & $\mathrm{cm}^{3} / \mathrm{g}$ & $\mathrm{nm}$ & $\mathrm{m} / \mathrm{g}$ & --- & Slit & Circ. & Spher. & $\%$ \\
\hline Al-SSP & 443.6 & 0.81 & 5.9 & 2.33 & 3.231 & 38.5 & 61.5 & 0 & 50 \\
1\%Mo/Al-SSP & 357.7 & 0.59 & 7.2 & 1.14 & 4.365 & 0 & $\left.81.7^{*}\right)$ & 18.3 & 100 \\
5\%Mo/Al-SSP & 492.4 & 0.58 & 3.9 & 3.81 & 3.311 & 34.5 & 65.5 & 0 & 40 \\
\hline
\end{tabular}

$S_{B E T}, V_{p}$ and $D_{p}$-total surface area, total pore volume and average pore size; $L_{V I}$-pore volume length index; $F_{d}-$ pore shape factor, Con.-Cdegree of conversion, $\left.{ }^{*}\right) 81.7 \%=100 *\left(6.0-F_{d}\right) / 2$ [https://doi.org/10.3762/bxiv.2020.89.v1] .

within 16, 22, 36 and 48 hours. Data on the surface area, volume and size of micro and mesopore, as well as on the catalytic activity in phenol alkylation with tert-butanol are presented. Our $F_{d}$ calculations showed that sample C16 (25), which provides the maximum (93.2\%) phenol conversion, has a pore shape closest to circular $(F=4863)$ and both $L_{s i}$ and $L_{v i}$ have the highest values.

The rare data presented in the article is the size of micropores. The micropore shape factor was in the range $f_{m i}=1170-1593$, which means a fragmentary slit shape. Together with $S_{m i}, V_{m i}$ it allows comparing STD-values of terms of Equations (3) and (4). The dependences of $F_{m e}$ on $V_{m e} / S_{m e}$ and $f_{m i}$ on $V_{m i} / S_{m i}$ were tested. The direct correlation between $F_{m e}$ and $V_{m e} / S_{m e}$ (not shown) means that the fluctuations of both parameters are summed up in the STD fluctuations of their product $D_{m e} f_{m i}$ versus $V_{m i}$ gives an inverse correlation (not shown), i.e. they oscillate in opposite directions, and the standard deviation of their product $D_{m i}$ can be obtained by subtracting the smaller value from the larger one (Table 9).

Proximity is visible: a) for mesopores-the STD of size value $(19.8 \%)$ with the sum $(20.7 \%)$ of STD-s of shape factor (9.9\%) and the Volume/Surface ratio $(10.8 \%)$; b) for micropores-the STD of size $(8.1 \%)$ with difference $(8 \%)$ between STD-s of shape factor (13.9\%) and the Volume/Surface ratio (5.9\%). Once again, we note the selective response of meso- and micro-textural parameters to the processing variables.

6) Ding et al. [36] used six $\gamma-\mathrm{Al}_{2} \mathrm{O}_{3}$ supports (samples $\mathrm{A} 1 \div \mathrm{A} 6$ ) from various suppliers to prepare a $\mathrm{FeK} / \mathrm{Al}_{2} \mathrm{O}_{3}$ catalyst (samples $\mathrm{C} 1 \div \mathrm{C} 6$ ) for hydrogenation of $\mathrm{CO}_{2}$ to hydrocarbons. The textural properties and the results of catalytic tests are presented. We plotted the dependence of the pore shape factor of the catalyst $F_{d c}$ on a similar $F_{d s}$ value of the support (Figure 9).

The highest $\mathrm{CO}_{2}$ conversion (54.4\%) and selectivity of $\mathrm{C} 5+$ hydrocarbons $(31.1 \%)$ were achieved for the sample with $F_{d s}=3.988$ and $F_{d c}=3.950$, i.e. when the pores of the catalyst inherited the circular pore shape of the support. The worst result ( $\approx 40 \%$ conversion ([36], Figure 7$)$ ) was obtained by a sample clearly separated in Figure 9, prepared on a support with $F_{d s}=5.473$ (74\% of spherical motive) and having $F_{d c}=4.622$ (31\% of spherical surface).

7) Zubizarreta et al. [24] investigated the adsorption of $\mathrm{H}_{2}$ in the two menshioned above (Section 3.2.2) series of $\mathrm{Ni}$-doped carbon xerogels with pore diameters of 
Table 9. Sum and difference of STD-s of terms of equations $D_{m e}=F_{m e} *\left(V_{m e} / S_{m e}\right)$ and $D_{m i}$ $=f_{m i} *\left(V_{m i} / S_{m i}\right)$.

\begin{tabular}{cccccc}
\hline & \multicolumn{5}{c}{ Parameter } \\
\cline { 2 - 6 } Porosity & $\begin{array}{c}\text { Shape } \\
\text { factor }\end{array}$ & $\begin{array}{c}\text { Volume/Surface } \\
\text { area }\end{array}$ & Size & STDs sum & STDs difference \\
\cline { 2 - 6 } & \multicolumn{5}{c}{ STD, \% } \\
\hline meso & 9.9 & 10.8 & 19.8 & $9.9+10.8=20.7$ & --- \\
micro & 13.9 & 5.9 & 8.1 & --- & $13.9-5.9=8.0$ \\
\hline
\end{tabular}

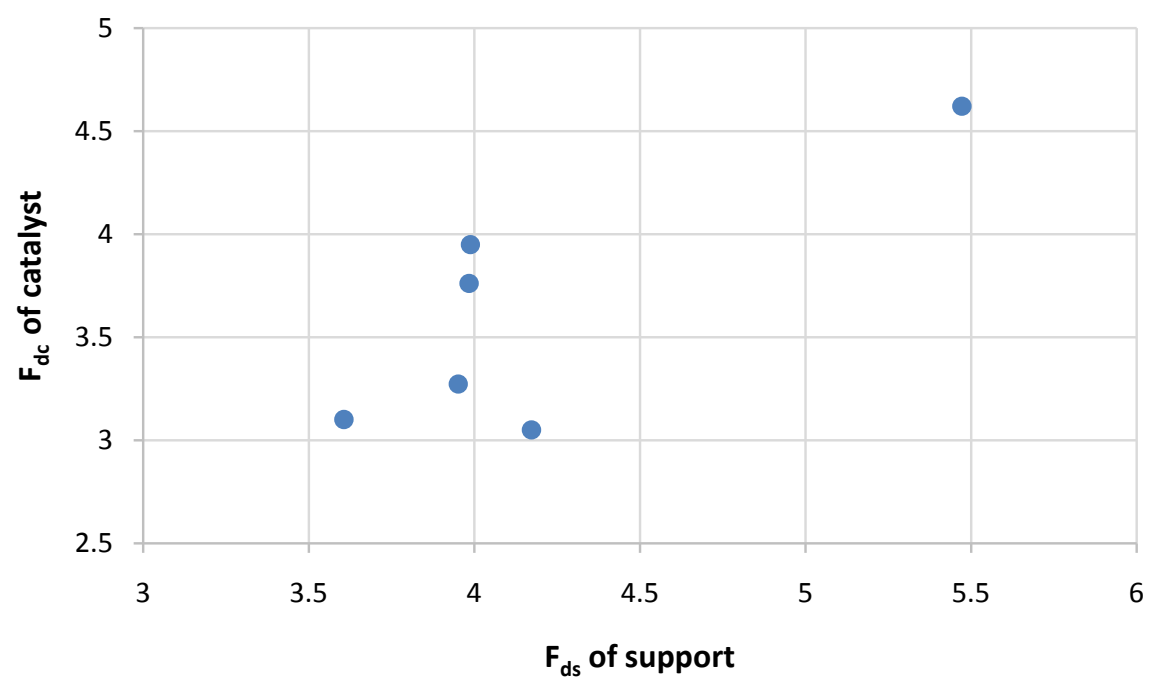

Figure 9. $F_{d c}$ of the $\mathrm{FeK} / \mathrm{Al}_{2} \mathrm{O}_{3}$ catalyst vs. $F_{d s}$ of the $\mathrm{Al}_{2} \mathrm{O}_{3}$ support. Based on Ding et al. [37] data.

$16 \mathrm{~nm}$ (series CX16) and $45 \mathrm{~nm}$ (series CX45). The uptake of $\mathrm{H}_{2}$ depends on the $\mathrm{H}_{2}$ spillover, i.e. $\mathrm{H}_{2}$ transfer from the metal catalyst to the carbon support. The sample with the highest adsorption capacity was CX16AOXI $\left(D_{p}=16 \mathrm{~nm}\right.$, designations: A-chemically activated carbon xerogel, $\mathrm{OX}-$ oxidized $\mathrm{HNO}_{3}, \mathrm{I}-\mathrm{Ni}$ doped by impregnation). To identify the causes, we compared this sample with a similarly treated CX45AOXI sample $\left(D_{p}=45 \mathrm{~nm}\right)$ using $L_{s i} L_{v i}$ and $F_{d}$ (Table 10).

The pore length of the sample CX45AOXI (and all CX45 samples with wide pores) is much shorter that of the pores of $16 \mathrm{~nm}$. This creates a very strong surface corrugation of wide pores, $D_{p}=45 \mathrm{~nm}$, compared to narrow pores, $D_{p}=16$ $\mathrm{nm}\left(F_{d}=28\right.$ against 17.1).

Recall that smooth cylindrical pores have $F_{d}=4$; comparing this number with the obtained values, we can say that for a high adsorption capacity, the surface should be highly corrugated $\left(F_{d}=17.1\right)$, but $F_{d}=28$ indicates exessive corrugation, which worsens the spillover of $\mathrm{H}_{2}$.

\subsection{Sonochemical Effect on the Texture of the WGS reaction Catalyst}

Perkas et al. [38] improved the $\mathrm{CuO}-\mathrm{ZnO} / \mathrm{TiO}_{2}$ catalyst for the WGS reaction by 
Table 10. Pore lengths indices $L_{s i}, L_{v i}$ and pore shape factors $F_{d}$-s of a pair of Ni-doped carbon xerogels. Based on Zubizarreta et al. [24] data.

\begin{tabular}{cccc}
\hline \multirow{2}{*}{ Samplea } & \multicolumn{3}{c}{ Parameter } \\
\cline { 2 - 4 } & $L_{s i} \mathrm{E}-09, \mathrm{~m} / \mathrm{g}$ & $L_{v i} \mathrm{E}-09, \mathrm{~m} / \mathrm{g}$ & $F_{d}$ \\
\hline CX16AOXI & 100.2 & 5.9 & 17.1 \\
CX45AOXI & 35.6 & 1.3 & 28.0 \\
\hline
\end{tabular}

$L_{s i} L_{v i}$-indices of pore both surface and volume lengths, $F_{d}$-generalized shape factor.

sonochemical method. The best results were achieved with catalysts supported on commercial $\mathrm{TiO}_{2}$ Degussa P25 support. Among the carriers tested, the P25 has the smallest pore diameter $(1 \mathrm{~nm})$ and $F_{d}=0.5$, (i.e. slit pores with a very fragmented surface), but the longest pore volume $\left(L_{v i}=9 \mathrm{E}+10 \mathrm{~m} / \mathrm{g}\right)$.

Sonochemical treatment led to an increase in $D_{p}$ from 1 to $8.6 \mathrm{~nm}$ and $F_{d}$ from 0.5 to 1.944 , that is, to pores with a slot pores with a smooth surface; $L_{v i}$ decreased from $9 \mathrm{E}+10$ to $0.31 \mathrm{E}+10 \mathrm{~m} / \mathrm{g}$, i.e. 30 times. Apparently, sonochemical treatment smoothes surface irregularities of the pore, stretching it along the perimeter and tightening it along the axis.

\section{Conclusions}

The ability of the generalized parameters (GP) of porous materials to divide an array of samples into series with similar properties (as known Similarity Numbers), to highlight special samples, a critical point in dependencies and structural nuances, is shown. New GPs proposed. An average pore size is defined as the product of two GPs: the generalized shape factor (for any size) and the generalized size (for any shape); the latter is the reciprocal of the known volumetric surface. Pore length indices have been proposed.

The standard deviation (STD, \%) of the textural parameter in a series of experiments was called its serial GP. This made it possible to propose the concept of "surface topography" $V_{m i} / S_{B E T}\left(\mathrm{~cm}^{3} / \mathrm{m}^{2}\right)$, where the volume of micropores fluctuates together with the surface area and is a more stable parameter than the volume of micropores $V_{m i}\left(\mathrm{~cm}^{3} / \mathrm{g}\right)$, where the volume of micropores fluctuates along with the weight (density) of the material.

In a broad sense, STD can be applied to a series of any parameters in any process.

All previously and now proposed GPs were used. Tested were plant carbons, carbon replicas, ordered, disordered and foamed $\mathrm{SiO}_{2}$, alumina and different catalysts. The correlations between the efficiency of some catalytic reactions (adsorption) with GPs have been studied. Typically, higher conversion rates are achieved in circular and long pores. Sonochemical treatment of the $\mathrm{CuO}-\mathrm{ZnO} / \mathrm{TiO}_{2}$ catalyst smoothes the surface irregularities of the pore surface, greatly expanding the pores in the radial direction and narrowing them in the axial direction, what explains its effectiveness in the WGS reaction.

It was found, in particular, that: 1) in the preparation of SBA-15, the short- 
chain copolymer $\mathrm{EO}_{5} \mathrm{PO}_{70} \mathrm{EO}_{5}$ acts similar to post-synthesis heating; 2) SBA-15 walls of the same thickness can differ in intra-wall porosity and the surfaces of micropores; 3) Calcination and treatment with an alkaline solution make the round pores of SBA-15 close to slotted ones; 4) Direct inclusion of $\mathrm{Al}$ into the structure of SBA-15 prevents pores flattening; 5) Some metals (Al, Fe), included in MCM-41 or SBA-15 hosts can occupy the intra-wall space; 6) Grafting MCM41 with $0.65 \mathrm{wt} \%$ of $\mathrm{Ti}$ smoothes the pores, increases the volume length, but almost does not change the surface length; 7) The reaction of silanol groups of uncalcined SBA-15 with carboxylic groups led to a decrease in the length of the pore surface, but an increase in the length of the pore volume; 8) Cellular silica foams do not have intra-wall pores; 9) The critical temperature of carbon calcination was found: up to $800^{\circ} \mathrm{C} V_{m i} / S_{B E T}$ does not change, but after $800^{\circ} \mathrm{C} V_{m i}$ grows faster than $\left.S_{B E T} ; 10\right) V_{m i} / S_{B E T}$ separates carbon samples with the highest and lowest methane uptake; 11) SBA-15 carbon replica from sucrose repeated topography SBA-15, while polyfurfuryl alcohol provides a smooth surface with much lower $V_{m i l}\left(S_{B E T} ; 12\right)$ Excessive corrugation of carbon xerogel surface impairs $\mathrm{H}_{2}$ spillover.

Thus, the use of GPs significantly expands knowledge about the influence of processing conditions of porous materials on their properties, sorption and catalytic efficiency.

\section{Declarations}

No funds, grants, or other support was received.

\section{Ethics Approval}

No figures, tables or text passages have been used that require permission.

\section{Conflicts of Interest}

The author declares no conflicts of interest regarding the publication of this paper.

\section{References}

[1] Vradman, L., Titelman, L. and Herscowitz, M. (2006) Size Effect on SBA-15 Microporosity. Microporous and Mesoporous Materials, 93, 313-317. https://doi.org/10.1016/j.micromeso.2006.03.014

[2] Titelman, L. (2012) Generalized Processing-Structural Functions for Porous Materials. Journal of Porous Materials, 19, 1-13. https://doi.org/10.1007/s10934-010-9440-y

[3] Titelman, L. (2019) Generalized Variables for Both Porous and Ordered Mesoporous Materials. SN Applied Sciences, 1, Article No. 1294. https://doi.org/10.1007/s42452-019-1318-2

[4] Gibson, F.J. and Ashby, M.F. (1997) Cellular Solids: Structure and Properties. 2nd Edition, Cambridge University Press, Cambridge.

https://doi.org/10.1017/CBO9781139878326 
[5] Williford, R.E., Li, X.S., Addleman, R.S., Fryxell, G.E., Baskaran, S., Birnbaum, J.C., Coyle, C., Zemanian, T.S., Wang, C. and Courtney, A.R. (2005) Mechanical Stability of Templated Mesoporous Silica Thin Films. Microporous and Mesoporous Materials, 85, 260-266. https://doi.org/10.1016/j.micromeso.2005.06.024

[6] Sozer, N., Dogan, H. and Kokini, J.J. (2011) Textural Properties and Their Correlation to Cell Structure in Porous Food Materials. Journal of Agricultural and Food Chemistry, 59, 1498-1507. https://doi.org/10.1021/jf103766x

[7] Titelman, L.I. (1990) Some Relationships between the Structural and Mechanical Characteristics of Catalysts and Sorbents. Nauchnye Osnovy Prigotovleniya i Tekhnologii Katalizatorov (Sbomik Nauchnych Trudov) [Scientific Foundations of the Preparation and Technology of Catalysts (Collection of Scientific Reports)]. Institute of Catalysis, Siberian Division of Academy of Sciences of the USSR, Novosibirsk, 62-78.

[8] Titelman, L. and Levitskaya, N. (1987) Selective Effect of Technological and Operational Factors on the Mechanical Properties of Catalysts. Russian Journal of Applied Chemistry, 2666-2670.

[9] Surface-Area-to-Volume Ratio. Wikipedia.

[10] Gómez-Gualdrón, D., Wilmer, C., Farha, O., Hupp, J. and Snurr, R. (2014) Exploring the Limits of Methane Storage and Delivery in Nanoporous Materials. The Journal of Physical Chemistry C, 118, 6941-6951. https://doi.org/10.1021/jp502359q

[11] Stewart, L., Lu, W., Wei, Z.W., Ila, D., Padilla, C. and Zhou, H.C. (2017) A Zirconium Metal-Organic Framework with an Exceptionally High Volumetric Surface Area. Dalton Transactions, 46, 14270-14276 https://doi.org/10.1039/C7DT03394I

[12] Sahoo, P. (2011) Chapter 1-Surface Topography. In: Davim, J.P., Ed., Tribology for Engineers. A Practical Guide, Woodhead Publishing, Cambidge, 1-32. https://doi.org/10.1533/9780857091444.1

[13] Li, J., Xu, X., Hao, Z. and Zhao, W. (2008) Mesoporous Silica Supported Cobalt Oxide Catalysts for Catalytic Removal of Benzene. Journal of Porous Materials, 15, 163-169. https://doi.org/10.1007/s10934-007-9119-1

[14] Feng, Y., Yang, W. and Chu. W. (2015) A Study of $\mathrm{CO}_{2}$ Methanation over Ni-Based Catalysts Supported by CNTs with Various Textural Characteristics. International Journal of Chemical Engineering, 2015, Article ID: 795386. https://doi.org/10.1155/2015/795386

[15] Ratso, S., Sahraie, N.R., Sougrati, M.T., Kaarik, M., Kook, M., Saar, R., Paiste, P., Jia, Q., Leis, J., Mukerjee, S., Jaouen, F. and Tammeveski, K. (2018) Synthesis of Highly-Active Fe-N-C Catalysts for PEMFC with Carbide-Derived Carbons. Journal of Materials Chemistry A, 6, 14663-14674. https://doi.org/10.1039/C8TA02325E

[16] Zhao, D., Feng, J., Huo, Q., Melosh, N., Fredrickson, G.H., Chmelka, B.F. and Stucky, G.D. (1998) Triblock Copolymer Syntheses of Mesoporous Silica with Periodic 50 to 300 Angstrom Pores. Science, 279, 548-552.

https://doi.org/10.1126/science.279.5350.548

[17] Klimova, T., Esquivel, A., Reyes, J., Rubio, M., Bokhimi, X. and Aracil, J. (2006) Factorial Design for the Evaluation of the Influence of Synthesis Parameters upon the Textural and Structural Properties of SBA-15 Ordered Materials. Microporous and Mesoporous Materials, 93, 331-343.

https://doi.org/10.1016/j.micromeso.2006.03.016

[18] Putz, A.M., Cecilia, S., Ianăşi, C., Dudás, Z., Székely, K., Plocek, J., Sfârloagă, P., Săcărescu, L. and Almásy, L. (2015) Pore Ordering in Mesoporous Matrices Induced 
by Different Directing Agents. Journal of Porous Materials, 22, 321-331. https://doi.org/10.1007/s10934-014-9899-Z

[19] Schmidt-Winkel, P., Lukens, W., Yang, P., Margolese, D., Lettow, J., Ying, J. and Stucky, G. (2000) Microemulsion Templating of Siliceous Mesostructured Cellular Foams with Well-Defined Ultralarge Mesopores. Chemistry of Materials, 12, 686696. https://doi.org/10.1021/cm991097v

[20] Zukerman, R., Vradman, L., Titelman, L., Weidenthaler, C., Landau, M. and Herskowitz, M. (2008) Effect of Silica Wall Microporosity on the State and Performance of $\mathrm{TiO}_{2}$ Nanocrystals in SBA-15 Matrix. Microporous and Mesoporous Materials, 116, 237-245. https://doi.org/10.1016/j.micromeso.2008.04.011

[21] Dubinin, M.M. (1960) The Potential Theory of Adsorption of Gases and Vapors for Adsorbents with Energetically Nonuniform Surfaces. Chemical Reviews, 60, 235-241. https://doi.org/10.1021/cr60204a006

[22] Gadiou, R., Saadallah, S.E., Piquero, T., David, P., Parmentier, J. and Vix-Guterl, C. (2005) The Influence of Textural Properties on the Adsorption of Hydrogen on Ordered Nanostructured Carbons. Microporous and Mesoporous Materials, 79, 121128. https://doi.org/10.1016/j.micromeso.2004.10.034

[23] Mostazo-López, M., Salinas-Torres, D., Ruiz-Rosas, R., Morallón, E. and CazorlaAmorós, D. (2019) Nitrogen-Doped Superporous Activated Carbons as Electrocatalysts for the Oxygen Reduction Reaction. Materials, 12, Article ID: 1346. https://doi.org/10.3390/ma12081346

[24] Zubizarreta, L., Menéndez, J.A., Job, N., Marco-Lozar, J.P., Pirard, J.P., Pis, J.J., Linares-Solano, A., Cazorla-Amorós, D. and Arenillas, A. (2010) Ni-Doped Carbon Xerogels for $\mathrm{H}_{2}$ Storage. Carbon, 48, 2722-2733.

https://doi.org/10.1016/j.carbon.2010.03.068

[25] Węgrzyniak, A., Jarczewski, S., Kuśtrowski, P., et al. (2018) Influence of Carbon Precursor on Porosity, Surface Composition and Catalytic Behaviour of CMK-3 in Oxidative Dehydrogenation of Propane to Propene. Journal of Porous Materials, 25, 687696. https://doi.org/10.1007/s10934-017-0482-2

[26] Ponomarenko, I., Parfenov, V., Zaitseva, Y., Zharkov, S. and Kirik S. (2014) Template Synthesis of CMK-3 Nanostructured Carbon Material and Study of Its Properties. Glass Physics and Chemistry, 40, 79-87. https://doi.org/10.1134/S1087659614010180

[27] Lee, H.I., Kim, J.H, You, D.J., Lee, J.E., Kim, J.M., Ahn, W.S. Pak, C., Joo, S.H., Chang, H. and Seung, D. (2008) Rational Synthesis Pathway for Ordered Mesoporous Carbon with Controllable 30- to 100-Angstrom Pores. Advanced Materials, 20, 757-762. https://doi.org/10.1002/adma.200702209

[28] Arshad, S., Ngadi, N., Aziz, A., Amin, N., Jusoh, M. and Wong, S. (2016) Preparation of Activated Carbon from Empty Fruit Bunch for Hydrogen Storage. Journal of Energy Storage, 8, 257-261. https://doi.org/10.1016/j.est.2016.10.001

[29] Alam, N. and Mokaya, R. (2010) Evolution of Optimal Porosity for Improved Hydrogen Storage in Templated Zeolite-Like Carbons. Energy \& Environmental Science, 3, 1773-1781. https://doi.org/10.1039/c0ee00154f

[30] Pagketanang, T., Artnaseaw, A., Wongwicha, P. and Thabuot, M. (2015) Microporous Activated Carbon from KOH-Activation of Rubber Seed-Shells for Application in Capacitor Electrode. Energy Procedia, 79, 651-656. https://doi.org/10.1016/j.egypro.2015.11.550

[31] Bastos-Neto, M., Canabrava, D.V., Torres, A.E.B., Rodriguez-Castellón, E., JiménezLópez, A., Azevedo, D.C.S. and Cavalcante C.L. (2007) Effects of Textural and Sur- 
face Characteristics of Microporous Activated Carbons on the Methane Adsorption Capacity at High Pressures. Applied Surface Science, 253, 5721-5725. https://doi.org/10.1016/j.apsusc.2006.12.056

[32] Yue, Y.H., Gedeon, A., Bonardet, J.L., d’Espinose, J.B., Melosh, N. and Fraissard, J. (2000) Direct Incorporation of A1 in SBA Mesoporous Materials: Characterization, Stability and Catalytic Activity. Studies in Surface Science and Catalysis, 129, 209218. https://doi.org/10.1016/S0167-2991(00)80216-5

[33] La-Salvia, N., Lovón-Quintana, J., Lovón, A. and Valença, G. (2017) Influence of Aluminum Addition in the Framework of MCM-41 Mesoporous Molecular Sieve Synthesized by Non-Hydrothermal Method in an Alkali-Free System. Materials Research, 20, 9 p. https://doi.org/10.1590/1980-5373-mr-2016-1064

[34] Palumbo, C., Tiozzo, C., Ravasio, N., Psaro, R., Carniato, F., Bisio, C. and Guidotti, M. (2016) An Efficient Epoxidation of Terminal Aliphatic Alkenes over Heterogeneous Catalysts: When Solvent Matters. Catalysis Science \& Technology, 6, 3832 3839. https://doi.org/10.1039/C5CY01639H

[35] Chanchuey, T., Autthanit, Ch. and Jongsomjit, B. (2016) Effect of Mo-Doped Mesoporous Al-SSP Catalysts for the Catalytic Dehydration of Ethanol to Ethylene. Journal of Chemistry, 2016, Article ID: 9672408. https://doi.org/10.1155/2016/9672408

[36] Xu, L., Duan, L., Liu, Z., et al. (2013) Influence of Al Content on Textural Properties and Catalytic Activity of Hierarchical Porous Aluminosilicate Materials. Bulletin of Materials Science, 36, 1291-1295. https://doi.org/10.1007/s12034-013-0585-6

[37] Ding, F., Zhang, A., Liu, M., Yi, Z., Li, K., Guo, X. and Song, C. (2014) $\mathrm{CO}_{2}$ Hydrogenation to Hydrocarbons over Iron-Based Catalyst: Effects of Physicochemical Properties of $\mathrm{Al}_{2} \mathrm{O}_{3}$ Supports. Industrial \& Engineering Chemistry Research, 53, 17563 17569. https://doi.org/10.1021/ie5031166

[38] Perkas, N., Gunawan, P. Amirian, G., Wang, Z., Zhong, Z. and Gedanken, A. (2014) The Sonochemical Approach Improves the $\mathrm{CuO}-\mathrm{ZnO} / \mathrm{TiO}_{2}$ Catalyst for WGS Reaction. Physical Chemistry Chemical Physics, 16, 7521-7530. https://doi.org/10.1039/C3CP55307H 


\section{Article Highlights}

Generalized parameters of porous materials distinguish between series, special samples and structural nuances.

The standard deviation of a parameter in a series is its serial generalized parameter.

The surface topography $\left(\mathrm{cm}^{3} / \mathrm{m}^{2}\right)$ is a more stable parameter than the volume of micropores $\left(\mathrm{cm}^{3} / \mathrm{g}\right)$.

The average pore size is the product of the generalized pore size and the generalized shape factor.

\section{Nomenclature}

$D_{h}$-hydraulic circular pore diameter $(\mathrm{nm})=4000 V_{p}\left(\mathrm{~cm}^{3} / \mathrm{g}\right) / S_{B E T}\left(\mathrm{~m}^{2} / \mathrm{g}\right)$

$D_{h}$-hydraulic circular pore diameter $(\mathrm{m})=4 V_{p}\left(\mathrm{~m}^{3} / \mathrm{g}\right) / S_{B E T}\left(\mathrm{~m}^{2} / \mathrm{g}\right)$

$D_{p}$-pore size $(\mathrm{nm})$

$F$-generalized pore shape factor $\left(\mathrm{nm}^{*} \mathrm{~m}^{2} / \mathrm{cm}^{3}\right)=D_{p}(\mathrm{~nm}) * S_{B E T}\left(\mathrm{~m}^{2} / \mathrm{g}\right) / V_{p}\left(\mathrm{~cm}^{3} / \mathrm{g}\right)$

$F_{d}-$ generalized pore shape factor (dimensionless) $=D_{p}(\mathrm{~m}) * S_{B E T}\left(\mathrm{~m}^{2} / \mathrm{g}\right) / V_{p}\left(\mathrm{~m}^{3} / \mathrm{g}\right)$

GP-generalized parameter

$L_{s}$ - circular pore surface length $\left(\mathrm{m}^{2} /(\mathrm{g} * \mathrm{~nm})\right)=S_{B E T}\left(\mathrm{~m}^{2} / \mathrm{g}\right) / \pi D_{p}(\mathrm{~nm})$

$L_{s}$-circular pore surface length $(\mathrm{m} / \mathrm{g})=S_{B E T}\left(\mathrm{~m}^{2} / \mathrm{g}\right) / \pi D_{p}(\mathrm{~m})$

$L_{s L}=$ pore surface length index $\left(\mathrm{m}^{2} /(\mathrm{g} * \mathrm{~nm})\right)=S_{B E T}\left(\mathrm{~m}^{2} / \mathrm{g}\right) / D_{p}(\mathrm{~nm})$

$L_{S I}-$ pore surface length index $(\mathrm{m} / \mathrm{g})=S_{B E T}\left(\mathrm{~m}^{2} / \mathrm{g}\right) / D_{p}(\mathrm{~m})$

$L_{V}$ - circular pore volume length $\left(\mathrm{cm}^{3} /\left(\mathrm{g}^{\star} \mathrm{nm}^{2}\right)\right)=V_{p} /\left((\pi / 4) D_{p}^{2}\right)$

$L_{V}-$ circular pore volume length $(\mathrm{m} / \mathrm{g})=V_{p} /\left((\pi / 4) D_{p}^{2}\right)$

$L_{V I}-$ pore volume length index $\left(\mathrm{cm}^{3} /\left(\mathrm{g}^{*} \mathrm{~nm}^{2}\right)\right)=V_{p} / D_{p}^{2}$

$L_{V I}$-pore volume length index $\left.(\mathrm{m} / \mathrm{g})\right)=V_{p}\left(\mathrm{~m}^{3}\right) / D_{p}^{2}\left(\mathrm{~m}^{2}\right)$

$\mathrm{MOF}$ - metal-organic framework

OMM-ordered mesoporous materials

$S_{t}$-total surface area $\left(\mathrm{m}^{2} / \mathrm{g}\right)$

$S_{m l}-$ micropore surface area $\left(\mathrm{m}^{2} / \mathrm{g}\right)$

$t$-average wall thickness $(\mathrm{nm})$

$V_{t}$-total volume $\left(\mathrm{cm}^{3} / \mathrm{g}\right)$

$V_{i w}$-intra-wall pore volume $\left(\mathrm{cm}^{3} / \mathrm{g}\right)$

$V_{p}$-open pore total specific volume $\left(\mathrm{cm}^{3} / \mathrm{g}\right)$

$V_{s k}$-skeletal wall volume $\left(\mathrm{cm}^{3} / \mathrm{g}\right)$

$V_{W}=V_{s k}+V_{i W}-$ apparent wall volume $\left(\mathrm{cm}^{3} / \mathrm{g}\right)$

$X$-independent process generalized variable (sample, run №)

$Y$-generalized textural parameter

$y$-single textural parameter

\section{Supportig Information}

SI-GPs calculations based on Zukerman et al. data [20], https://doi.org/10.3762/bxiv.2020.89.v1, not published. 